\title{
Prostatic Acid Phosphatase Reduces Thermal Sensitivity and Chronic Pain Sensitization by Depleting Phosphatidylinositol 4,5-Bisphosphate
}

\author{
Nathaniel A. Sowa, ${ }^{1,2}$ Sarah E. Street, ${ }^{1}$ Pirkko Vihko, ${ }^{3,4}$ and Mark J. Zylka ${ }^{1}$ \\ ${ }^{1}$ Department of Cell and Molecular Physiology, University of North Carolina Neuroscience Center, and ${ }^{2}$ Curriculum in Neurobiology, University of North

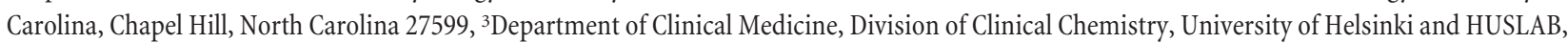 \\ FI-00014 Helsinki, Finland, and ${ }^{4}$ Research Center for Molecular Endocrinology, University of Oulu, FI-90014 Oulu, Finland
}

\begin{abstract}
Prostatic acid phosphatase (PAP) is expressed in nociceptive dorsal root ganglion (DRG) neurons, functions as an ectonucleotidase, and generates adenosine extracellularly. Here, we found that PAP inhibits noxious thermal sensitivity and sensitization that is associated with chronic pain through sustained activation of the adenosine $A_{1}$ receptor $\left(A_{1} R\right)$ and phospholipase $C$-mediated depletion of phosphatidylinositol 4,5-bisphosphate $\left(\mathrm{PIP}_{2}\right)$. In mice, intrathecal injection of PAP reduced $\mathrm{PIP}_{2}$ levels in DRGs, inhibited thermosensation through TRPV1, and enduringly reduced thermal hyperalgesia and mechanical allodynia caused by inflammation, nerve injury, and pronociceptive receptor activation. This included inhibitory effects on lysophosphatidic acid, purinergic (ATP), bradykinin, and protease-activated (thrombin) receptors. Conversely, $\mathrm{PIP}_{2}$ levels were significantly elevated in DRGs from $\mathrm{Pap}^{-1-}$ mice, and this correlated with enhanced thermal hyperalgesia and mechanical allodynia in $\mathrm{Pap}^{-1-}$ mice. To directly test the importance of PIP ${ }_{2}$ in nociception, we intrathecally injected $\mathrm{PIP}_{2}$ into mice. This transiently $(2 \mathrm{~h})$ elevated $\mathrm{PIP}_{2}$ levels in lumbar DRGs and transiently $(2 \mathrm{~h})$ enhanced thermosensation. Additionally, thermal hyperalgesia and mechanical allodynia were enduringly enhanced when $\mathrm{PIP}_{2}$ levels were elevated coincident with injury/pronociceptive receptor stimulation. Nociceptive sensitization was not affected if $\mathrm{PIP}_{2}$ levels were elevated in the absence of ongoing pronociceptive receptor stimulation. Together, our data suggest that $\mathrm{PIP}_{2}$ levels in DRGs directly influence thermosensation and the magnitude of nociceptive sensitization. Moreover, our data suggest there is an underlying "phosphoinositide tone" that can be manipulated by an adenosine-generating ectonucleotidase. This tone regulates how effectively acute nociceptive insults promote the transition to chronic pain.
\end{abstract}

\section{Introduction}

Nociceptive neurons in the dorsal root ganglia (DRGs) sense noxious thermal and mechanical stimuli and can be sensitized by diverse pronociceptive chemicals (Hucho and Levine, 2007; Basbaum et al., 2009). Once sensitized, animals often display long-lasting thermal hyperalgesia and mechanical allodyniatwo common symptoms of chronic pain.

\footnotetext{
Received April 27, 2010; revised June 2, 2010; accepted June 16, 2010.

This work was supported by grants to M.J.Z. from The Sloan Foundation, The Searle Scholars Program, The Klingenstein Foundation, The Whitehall Foundation, and Rita Allen Foundation, and National Institute of Neurological Disorders and Stroke (NINDS) Grant R01NS060725, and grants to P.V. from The Sigrid Juselius Foundation, The Finnish Cancer Foundation, and The Research Council for Medicine of the Academy of Finland. N.A.S. was supported by NINDS Grant F30NS063507 and Medical Scientist Training Program Grant T32GM008719. Confocal imaging was performed at the University of North Carolina-Chapel Hill Confocal Imaging Facility, which is cofunded by NINDS and National Institute of Child Health and Human Development Grant P30NS045892. Calcium imaging was performed at the Michael Hooker Microscopy Facility, which is funded by an anonymous private donor. M.J.Z. is a Rita Allen Foundation Milton E. Cassel Scholar. We thank Sang-Kyou Han for PLC $\beta 3$ (EGFP- and FLAG-tagged versions), Tamas Balla for PLC $\delta$-PH-GFP, Ira Milosevic for PIPK (mRFP-PIPK1- $\gamma$ ), David Julius for TRPV1-GFP, and Xinzhong Dong for TRPV1 $\triangle 42$ and HEK293-TRPV1 stable cells; Yvette Chuang, Bonnie Taylor-Blake, and Eric McCoy for expert technical assistance; and Paul Farel, Ben Philpot, and Anthony LaMantia for comments on this manuscript.

Correspondence should be addressed to MarkJ.Zylka, Department of Cell and Molecular Physiology, University of North Carolina Neuroscience Center, University of North Carolina, CB \#7545, Chapel Hill, NC 27599. E-mail: zylka@med.unc.edu.

DOI:10.1523/JNEUROSCI.2162-10.2010

Copyright $\odot 2010$ the authors $\quad 0270-6474 / 10 / 3010282-12 \$ 15.00 / 0$
}

Recently, we found that nociceptive neurons express two molecularly distinct ectonucleotidases that generate adenosine extracellularly by dephosphorylating AMP. These ectonucleotidases include the transmembrane (TM) isoform of prostatic acid phosphatase (PAP) (also known as ACPP) and ecto-5' -nucleotidase (NT5E) (also known as CD73) (Zylka et al., 2008; Sowa et al., 2010). Interestingly, PAP knock-out $\left(\mathrm{Pap}^{-1-}\right)$ mice, $\mathrm{Nt5} \mathrm{e}^{-1-}$ mice, and adenosine $A_{1}$ receptor knock-out $\left(A_{1} R^{-1-}\right)$ mice all display enhanced nociceptive responses after inflammation or nerve injury (Wu et al., 2005; Zylka et al., 2008; Sowa et al., 2010). These observations suggest that deficiencies in adenosine production or $A_{1} R$ signaling enhance nociceptive sensitization; however, the mechanism underlying these enhanced nociceptive responses is currently unknown.

The secretory isoform of PAP (S-PAP) also generates adenosine by dephosphorylating AMP (Vihko, 1978; Zylka et al., 2008; Sowa et al., 2009). When injected intrathecally, S-PAP has longlasting ( $3 \mathrm{~d}$ ) thermal antinociceptive effects in naive mice as well as long-lasting antihyperalgesic and antiallodynic effects in sensitized animals (Zylka et al., 2008; Sowa et al., 2009). These antinociceptive effects were transiently blocked by an $A_{1} R$ antagonist and were eliminated in $A_{1} R^{-1-}$ mice, indicating that S-PAP activates $A_{1} R$ over a sustained time period. 
Adenosine and $\mathrm{A}_{1} \mathrm{R}$ agonists have antinociceptive effects when administered acutely to rodents and humans (Eisenach et al., 2003; Sawynok, 2007). Additionally, acute $A_{1} R$ activation inhibits neurotransmitter release from nociceptive neurons, voltagegated calcium channels, and postsynaptic neurons in spinal cord (Dolphin et al., 1986; Li and Perl, 1994; Lao et al., 2001). Although these inhibitory mechanisms may account for some aspects of $A_{1} R$ mediated antinociception, inhibition of neurotransmission cannot readily explain why sustained $A_{1} R$ activation by PAP selectively inhibits noxious thermal sensitivity in naive mice without affecting mechanical sensitivity (Zylka et al., 2008; Sowa et al., 2009). This selectivity suggests that PAP might regulate thermal nociception by acting through a specific thermosensory channel.

Indeed, in our present study, we found that PAP acts via $A_{1} R$ to reduce the levels of phosphatidylinositol 4,5-bisphosphate $\left(\mathrm{PIP}_{2}\right)$ in cultured cells and in vivo. In turn, this reduction in $\mathrm{PIP}_{2}$ inhibits thermosensation, in part through the capsaicin and noxious heat receptor TRPV1 (supplemental Fig. S1, available at www.jneurosci.org as supplemental material) (Caterina et al., 1997, 2000; Davis et al., 2000). This mechanism is consistent with several studies showing that $\mathrm{PIP}_{2}$ is required for TRPV1 to function optimally in vitro (for review, see Rohacs et al., 2008). Pronociceptive G-protein-coupled receptors (GPCRs) also require $\mathrm{PIP}_{2}$ to signal, suggesting alterations in $\mathrm{PIP}_{2}$ might regulate sensitization through these receptors. Indeed, we found that PAP inhibited signaling and sensitization through diverse pronociceptive GPCRs by depleting PIP $_{2}$ (supplemental Fig. S1, available at www.jneurosci.org as supplemental material), with PIP $_{2}$ levels at the time of stimulation/injury enduringly influencing the level of nociceptive sensitization. Collectively, our experiments suggest $\mathrm{PIP}_{2}$ plays a central role in nociceptive mechanisms.

\section{Materials and Methods}

All procedures and behavioral experiments involving vertebrate animals were approved by the Institutional Animal Care and Use Committee at the University of North Carolina at Chapel Hill.

Molecular biology. Full-length expression constructs for mouse TM-PAP (nucleotides 64-1314 from GenBank accession number NM_207668) and human TM-PAP (nucleotides 51-1304 from GenBank accession number BC007460) were generated by reverse transcription (RT)-PCR amplification using C57BL/6 mouse trigeminal cDNA or human placental cDNA (Clontech) as template and Phusion polymerase. The red fluorescent protein mCherry was then fused in-frame to the $\mathrm{C}$ terminus of all TM-PAP constructs. Mouse TM-PAP(H12A) was generated by PCRbased mutagenesis using mouse TM-PAP as template (His12 corresponds to His 43 of the mPAP preprotein). This active site mutant was previously described and lacks catalytic activity (Schneider et al., 1993; Ostanin et al., 1994). All constructs have a Kosak consensus sequence, were cloned into pcDNA3.1, and were sequence verified. We obtained additional constructs from others (see acknowledgments). We confirmed that adenosine receptors were expressed in Rat fibroblasts by RT-PCR $\left(\mathrm{A}_{1} \mathrm{R}\right.$ primers, 5'-CATTGGGCCACAGACCTACT and 5'-GGCAGAAGAGGGTGATACA).

Calcium imaging. Cell lines were grown on glass bottom culture dishes (MatTek; P35G-0-10-C) in DMEM containing 10\% fetal bovine serum, $100 \mathrm{U} / \mathrm{ml}$ penicillin, and $100 \mu \mathrm{g} / \mathrm{ml}$ streptomycin, and transfected with Lipofectamine Plus (Invitrogen) according to manufacturer's protocol. The total amount of DNA per transfection was adjusted to $1 \mu \mathrm{g}$ by adding pcDNA 3.1. After transfection (18-24 h), cells were loaded for $1 \mathrm{~h}$ at room temperature with $2 \mu \mathrm{M}$ fura-2 AM (Invitrogen; F-14185) in Hanks buffered salt solution (HBSS plus calcium and magnesium) assay buffer (HBSS plus 9 mM HEPES plus $11 \mathrm{~mm}$ D-glucose plus $0.1 \%$ fatty-acid free BSA, pH 7.4). Cells were then washed three times with HBSS assay buffer and sat for at least $30 \mathrm{~min}$ before imaging. A Nikon TE2000U microscope and Sutter DG4 light source were used to image calcium responses (excitation, $340 \mathrm{~nm} / 380 \mathrm{~nm}$; emission, $510 \mathrm{~nm}$ ). We manually pipetted and aspirated solutions for all calcium imaging experiments. Cells were stimulated with $1 \mu \mathrm{M}$ capsaicin, $100 \mathrm{~nm}$ lysophosphatidic acid (LPA), $1 \mathrm{U} / \mathrm{ml}$ thrombin (Thr), $10 \mu \mathrm{M}$ ATP, or $1 \mu \mathrm{M}$ bradykinin (BK) for $1-5 \mathrm{~min}$, washed in HBSS assay buffer for $1 \mathrm{~min}$, and then stimulated with $0.006 \%$ SDS to evoke maximal calcium responses for normalization. We did not use ionomycin to normalize responses because this calcium ionophore activates calcium-dependent phospholipase C (PLC) enzymes. As a result, the magnitude of the ionomycin-induced calcium response is also proportional to $\mathrm{PIP}_{2}$ levels in cells.

Calcium responses were normalized by calculating the area under the curve during ligand stimulation for each cell, and then dividing by the maximum SDS-evoked calcium response in each cell. These values were averaged over all cells for a given condition and then normalized relative to untransfected cells in the same field of view or relative to control cells (with the untransfected or control cell response set to 100\%).

For experiments with capsaicin, Rat 1 fibroblasts were transfected with TRPV1-green fluorescent protein (GFP) alone or TRPV1-GFP plus various constructs. The same amount of TRPV1-GFP was used for each transfection and the total amount of DNA per transfection was adjusted to $1 \mu \mathrm{g}$ by adding pcDNA 3.1. Cells were stimulated with $1 \mu \mathrm{M}$ capsaicin (from $100 \mathrm{~mm}$ stock in $100 \%$ DMSO, dissolved to final concentration in HBSS assay buffer) for $1 \mathrm{~min}$, followed by a 5 min wash in HBSS assay buffer, and then stimulation with $0.006 \%$ SDS.

For experiments with the $\mathrm{PIP}_{2}$ shuttle, Ratl fibroblasts were stimulated with $100 \mathrm{nM}$ LPA for $1 \mathrm{~min}$, followed by a 15 min wash with HBSS assay buffer plus $3 \mathrm{~nm} \mathrm{PIP}$ plus 3 nм Carrier 2 ( PIP $_{2}$ Shuttle kit; Echelon; P-9045) or HBSS assay buffer plus 3 nм Carrier 2 alone. Cells were then stimulated with $100 \mathrm{nM}$ LPA again, washed for 1 min with HBSS assay buffer, and stimulated with $0.006 \%$ SDS.

For thapsigargin experiments, HBSS assay buffer lacking calcium and containing $1 \mathrm{~mm}$ EGTA was used to eliminate extracellular calcium. The 10 $\mu \mathrm{M}$ thapsigargin was added for $5 \mathrm{~min}$, and the cells were then washed for 2 min with HBSS assay buffer and stimulated with $0.006 \%$ SDS. For pertussis toxin (PTX) experiments, Ratl fibroblasts were incubated for $18 \mathrm{~h}$ with 500 $\mathrm{ng} / \mathrm{ml}$ PTX before loading with fura-2 AM and stimulation with $100 \mathrm{nM}$ LPA. For experiments with adenosine receptor antagonists, PLC inhibitor [1-[6[[(17ß)-3-methoxyestra-1,3,5(10)-trien-17-yl]amino]hexyl]-1 H-pyrrole2,5-dione (U73122)], protein kinase C (PKC) inhibitor (staurosporine), or protein kinase A (PKA) inhibitor [(9S,10S,12R)-2,3,9,10,11,12-hexahydro10-hydroxy-9-methyl-1-oxo-9,12-epoxy- $1 \mathrm{H}$-diindolo[1,2,3-fg:3',2',1'-kl] pyrrolo[3,4-i] [1,6]benzodiazocine-10-carboxylic acid, hexyl ester (KT5720)], cells were incubated with antagonists for 3-4 h, loaded in the presence of antagonists/inhibitors with fura- $2 \mathrm{AM}$ for $1 \mathrm{~h}$, and then stimulated with pronociceptive ligands.

Electrophysiology. A HEK293-TRPV1 stable cell line (Kim et al., 2008) was transfected with TM-PAP-mCherry or TM-PAP(H12A)-mCherry. Patch-clamp recordings were made from mCherry-expressing cells using a Multiclamp 700B amplifier and pClamp 9.2 software as described previously (Campagnola et al., 2008). Heat ramps were generated by exchanging bath solution with a preheated solution via a two-to-one port. Solution was preheated with an in-line heater controlled by a TC-324B temperature controller modified for high temperature (Warner Instruments). Only one current recording was made per coverslip. The bath solution consisted of the following (in $\mathrm{mM}$ ): $140 \mathrm{NaCl}, 4 \mathrm{KCl}, 2 \mathrm{CaCl}_{2}, 2$ $\mathrm{MgCl}_{2}, 10 \mathrm{Na}$-HEPES, 5 glucose, $\mathrm{pH}$ 7.4, mOsm 295-310, and was perfused at a rate of $2-3 \mathrm{ml} / \mathrm{min}$ by gravity flow. Electrodes were pulled from borosilicate glass on a Sutter Instrument P-2000 and filled with intracellular solution that contained the following (in mM): $135 \mathrm{KCl}, 3 \mathrm{MgATP}$, 10 HEPES, $0.5 \mathrm{Na}_{2} \mathrm{ATP}, 1.1 \mathrm{CaCl}_{2}$, 2 EGTA, 5 glucose, with pH adjusted to 7.5 with $\mathrm{HCl}$ and osmolarity adjusted to $300 \mathrm{mOsm}$ with sucrose. Tip resistances ranged from 2.5 to $5 \mathrm{M} \Omega$. Series resistance was not compensated; however, recordings with series resistances $>15 \mathrm{M} \Omega$ were discarded.

$\mathrm{PIP}_{2}$ quantification. For quantification of $\mathrm{PIP}_{2}$ in vitro, HEK293 cells or Rat 1 fibroblasts were plated onto glass coverslips and transfected with the construct PLC $\delta$-PH-GFP along with indicated constructs using Lipofectamine Plus (Invitrogen), according to the manufacturer's protocol. Eighteen to $24 \mathrm{~h}$ later, the cells were fixed with $4 \%$ paraformaldehydePBS. Cells were imaged on a confocal microscope. GFP fluorescence on the plasma membrane (PM) of cells compared with the cytoplasm was 
quantified using ImageJ by taking cross-sectional averages of pixel intensity at the plasma membrane and dividing by the average of pixel intensity in the cytoplasm.

For quantification of $\mathrm{PIP}_{2}$ in DRGs, age-matched, adult male mice were injected intrathecally with $5 \mu \mathrm{l}$ of $15 \%$ lidocaine plus $50 \mathrm{U} / \mathrm{ml} \mathrm{hPAP}$ (250 mU total), 15\% lidocaine plus 3 nм Carrier 2 (Echelon; P-9C2), 15\% lidocaine plus 3 nм PIP 2 (Echelon; P-9045) plus 3 nм Carrier 2 or 15\% lidocaine alone. Before injection, an equimolar mixture of $\mathrm{PIP}_{2}$ plus Carrier 2 was incubated for $15 \mathrm{~min}$ at room temperature. Lidocaine causes transient (5-20 min.) paralysis of both hindlimbs, permitting us to visually determine whether each mouse received a successful intrathecal injection (we only quantified $\mathrm{PIP}_{2}$ levels in mice that showed transient bilateral paralysis). One day later, mice were killed and lumbar 3 (L3) to L6 DRGs were dissected bilaterally ( $n=8$ ganglia/sample) and placed in PBS on ice. For each sample, DRG wet weight was determined, and then lipids were extracted and quantified using the $\mathrm{PI}(4,5) \mathrm{P}_{2}$ Mass ELISA kit from Echelon (K-4500) following the manufacturer's protocol. PIP $_{2}$ levels were normalized by dividing by the wet weight of DRG tissue.

Behavior. Pap ${ }^{-1-}, A_{1} R^{-1-}$, and Trpv1 ${ }^{-1-}\left(\mathrm{B} 6.129 \mathrm{X} 1-\operatorname{Tr} p v 1^{\text {tm1Jul }} / \mathrm{J}\right)$ mice were backcrossed to $\mathrm{C} 57 \mathrm{BL} / 6$ mice for at least 10 generations. For all other experiments, male, C57BL/6 mice were purchased from The Jackson Laboratory. Male 2- to 4-month-old mice were used for all behavioral studies. All mice were acclimated to testing room, equipment, and experimenter for $1-3 \mathrm{~d}$ before behavioral testing. The experimenter was blind to genotype and drug treatment during behavioral testing. Thermal and mechanical sensitivity were measured as described previously (Zylka et al., 2008). For intrathecal drug delivery, $5 \mu$ l was injected into unanesthetized mice using the direct lumbar puncture method (Fairbanks, 2003). The complete Freund's adjuvant (CFA) model of inflammatory pain and the spared nerve injury (SNI) model of neuropathic pain were performed as described previously (Shields et al., 2003; Zylka et al., 2008).

Drugs. Secreted human PAP (S-hPAP) (Sigma-Aldrich; P1774) and heatinactivated S-hPAP were prepared as described previously (Zylka et al., 2008). The 18:1 lysophosphatidic acid (Avanti Polar Lipids; 857130) was dissolved in $0.9 \%$ ethanol and then diluted to final concentrations in either HBSS assay buffer (calcium imaging) or $0.9 \%$ saline (injections). ATP (Sigma-Aldrich; A26209) was dissolved in either HBSS assay buffer (calcium imaging) or $0.9 \%$ saline (injections). U73122 (Tocris; 1268) was first dissolved into DMSO, and then further diluted in $0.9 \%$ saline for intrathecal injection. The PI $(4,5) \mathrm{P}_{2}$ Shuttle PIP kit (Echelon; P-9045) was used to increase $\mathrm{PIP}_{2}$ levels in vivo. PtdIns $(4,5) \mathrm{P}_{2}$ di- $\mathrm{C}_{16}$ was first dissolved into $10 \%$ DMSO in $0.9 \%$ saline. Carrier 2 (Histone $\mathrm{H} 1$ ) was dissolved into $0.9 \%$ saline. Before injection, $\mathrm{PIP}_{2}$ and Carrier 2 were mixed in a 1:1 molar ratio and incubated at room temperature for $15 \mathrm{~min}$. Thrombin (Sigma-Aldrich; T4648) was first dissolved to $100 \mathrm{U} / \mathrm{ml}$ in $0.1 \%$ BSA and further diluted in HBSS assay buffer to final concentrations. BK was dissolved to $1 \mathrm{~mm}$ in DMSO and further diluted in HBSS assay buffer to final concentrations. PTX (Sigma-Aldrich; P7208) and caffeine (Sigma-Aldrich; C0750) were dissolved in water. 8-Cyclopentyl-1,3-dimethylxanthine (CPT) (Sigma-Aldrich; C102), 8-cyclopentyl-1,3-dipropylxanthine (CPX) (Sigma-Aldrich; C101), 7-(2-phenylethyl)-5-amino-2-(2-furyl)-pyrazolo-[4,3-e]-1,2,4-triazolo [1,5-c]pyrimidine (SCH 58261) (Sigma-Aldrich; S4568), 8-[4-[((4-cyanophenyl)carbamoylmethyl)oxy]phenyl]-1,3-di(n-propyl)xanthine hydrate (MRS 1754) (Sigma-Aldrich; M6316), 3-propyl-6-ethyl-5-[(ethylthio)carbonyl]-2-phenyl-4-propyl-3-pyridine carboxylate (MRS 1523) (SigmaAldrich; M1809), staurosporine (Sigma-Aldrich; S4400), KT5720 (Tocris; 1288), and U73122 (Tocris; 1268) were dissolved in DMSO and further diluted in HBSS assay buffer to final concentrations.

\section{Results}

\section{PAP inhibits activation of TRPV1}

We previously found that S-PAP reduced noxious thermal sensitivity by activating $A_{1} R$ for a sustained $3 \mathrm{~d}$ time period (Zylka et al., 2008; Sowa et al., 2009). Since TRPV1 functions as a noxious heat and capsaicin receptor (Caterina et al., 1997, 2000), we hypothesized that PAP might reduce thermal sensitivity by inhibiting TRPV1. To test this hypothesis, we transfected Rat1 fibro- blasts with TRPV1 and mouse TM-PAP, and then measured capsaicin-evoked responses with the calcium indicator fura-2 AM. We observed that both the amplitude and duration of the capsaicin-evoked calcium response was reduced by $25 \%$ in TMPAP-transfected cells relative to cells expressing TRPV1 alone (Fig. $1 A$ ). Inhibition was dependent on TM-PAP catalytic activity because capsaicin-evoked calcium responses were not inhibited in cells transfected with TM-PAP(H12A), a phosphatase-dead mutant of TM-PAP (Fig. $1 B$ ). Moreover, the $\mathrm{A}_{1} \mathrm{R}$-selective antagonist CPX blocked the effect of TM-PAP on capsaicin-evoked signaling (Fig. $1 B$ ) (Rat1 cells express $A_{1} R$ ) (data not shown). Last, heat-evoked current density through TRPV1 was reduced in cells expressing TM-PAP relative to cells expressing catalytically inactive TM-PAP(H12A) (Fig. 1C). All TM-PAP constructs were fused to the red fluorescent protein mCherry and were expressed at similar levels, but only the H12A mutant lacked catalytic activity (as assessed using enzyme histochemistry) (data not shown). Collectively, our data suggest that TM-PAP acts via $A_{1} R$ to reduce capsaicin- and heat-evoked activation of TRPV1.

Next, to determine whether PAP reduced noxious thermal sensitivity by acting through TRPV1 in vivo, we measured thermal withdrawal latencies in wild-type (WT) and Trpv1 ${ }^{-1-}$ mice before and after intrathecal injection of S-hPAP. As previously observed (Caterina et al., 2000), there were no significant differences at baseline between WT and $\operatorname{Trp} v 1^{-1-}$ mice when stimulating the hindpaw with radiant heat (Fig. 1D). After S-hPAP injection, paw withdrawal latency significantly increased (relative to baseline) at the $30 \mathrm{~min}$ time point and remained elevated for $3 \mathrm{~d}$ in WT mice (Fig. 1D), reproducing previous results (Zylka et al., 2008). In contrast, the thermal antinociceptive effect of S-hPAP was blunted in magnitude $(p<0.001$ by two-way ANOVA; relative to $\mathrm{WT}$ ) and duration ( $2 \mathrm{~d}$; relative to baseline) in $\operatorname{Trpv1} 1^{-1-}$ mice (Fig. 1D) (this difference between genotypes was independently reproduced in Fig. $1 F$, control paw). S-hPAP was equally effective at reducing mechanical allodynia in WT and Trp $v 1^{-/-}$mice after CFA-induced inflammation (Fig. $1 E$, black dashed line vs red dashed line), ruling out the trivial possibility that $\operatorname{Trp} v 1^{-1-}$ mice were less sensitive to all antinociceptive effects of S-hPAP. Although S-hPAP had long-lasting thermal antinociceptive effects in WT mice (Fig. $1 F$ ), we were unable to study the thermal antinociceptive effects of S-hPAP in Trpv1 $1^{-1-}$ mice because $\operatorname{Trpv1} 1^{-1-}$ mice did not develop thermal hyperalgesia after inflammation (Fig. $1 F$ ), as previously found by others (Caterina et al., 2000; Davis et al., 2000). Together, our cell-based and in vivo data suggest PAP reduces thermal sensitivity, in part, by inhibiting TRPV1.

\section{Activation of $\mathrm{A}_{1} \mathrm{R}$ by TM-PAP depletes PIP $_{2}$}

Our findings raised the question of how sustained, PAPdependent activation of $A_{1} R$ inhibited TRPV1 at a mechanistic level. $A_{1} R$ stimulation inhibits PKA via PTX-sensitive $G \alpha_{i / o^{-}}$ proteins. In addition, $A_{1} R$ stimulation activates PLC (including PLC $\beta 3$ ) via PTX-sensitive G $\beta \gamma$ subunits (Murthy and Makhlouf, 1995; Dickenson and Hill, 1998). PLC enzymes then hydrolyze $\mathrm{PIP}_{2}$ in the membrane to diacylglycerol (DAG) and inositol triphosphate $\left(\mathrm{IP}_{3}\right)$. These facts suggested that sustained activation of $\mathrm{A}_{1} \mathrm{R}$ might inhibit TRPV1 activity by inhibiting PKA, activating PKC (via DAG), depleting intracellular calcium stores (via $\mathrm{IP}_{3}$ ) or depleting $\mathrm{PIP}_{2}$ (via PLC activation). Although TRPV1 can be modulated by PKC and PKA (Bhave et al., 2002, 2003; Huang et al., 2006), TM-PAP did not inhibit TRPV1 through PKC or PKA pathways (supplemental Fig. S2 $A, B$, available at www.jneurosci.org as supplemental material). Nor did TM-PAP 
A

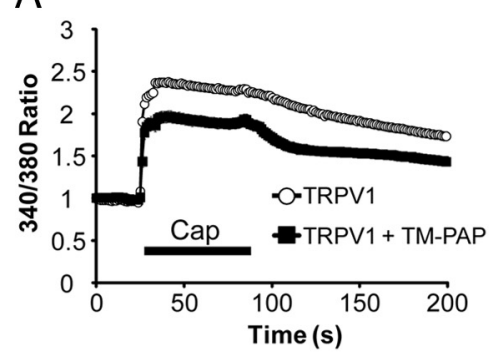

$\mathrm{D}$

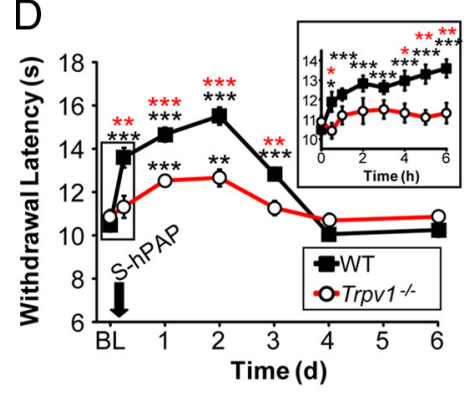

$\mathrm{B}$

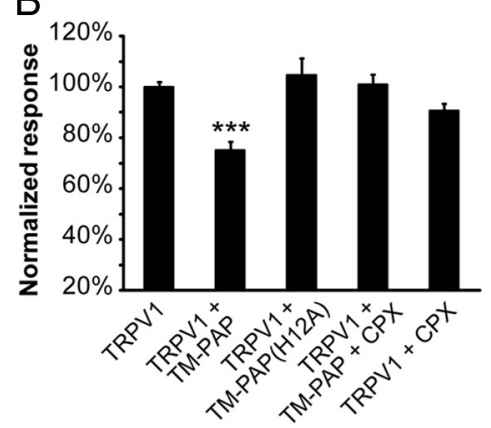

E

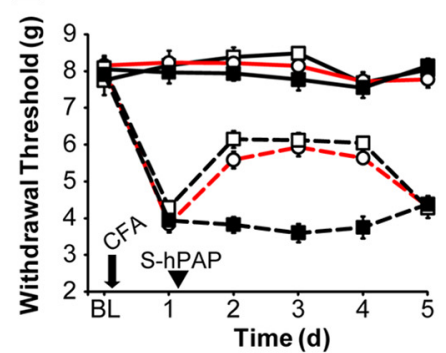

C

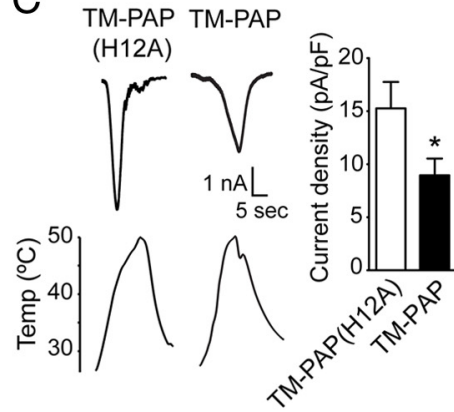

$\mathrm{F}$

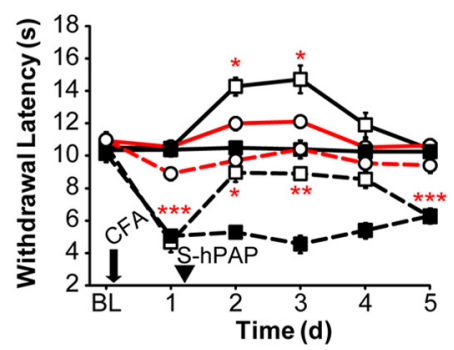

Control paw $\rightarrow-W T+$ S-hPAP

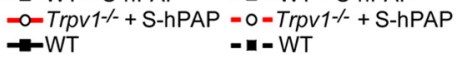

Figure 1. PAP reduces activity of the capsaicin and noxious heat receptor TRPV1. $A$, Capsaicin (1 $\mu \mathrm{m})$-evoked calcium responses in Rat1 fibroblasts expressing TRPV1 alone or with TM-PAP. The $340 / 380$ ratio is directly proportional to calcium concentration; $n=80$ cells per condition. $\boldsymbol{B}$, Normalized capsaicin-evoked calcium responses in Rat1 fibroblasts transfected with the indicated constructs. Where indicated, cells were incubated with CPX (5 $\mu \mathrm{m})$ for $3 \mathrm{~h}$ before stimulation; $n=40-60$ cells per condition; $t$ tests relative to TRPV1 only condition. $C$, Noxious heat-evoked currents and current density in HEK293-TRPV1 stable cells transfected with TM-PAP or the catalytically inactive H12A mutant; $n=20$ cells per condition. D, The hindpaws of WT (black) and Trpv $1-$ - - mice (red) were tested for noxious thermal sensitivity before [baseline (BL)] and after intrathecal injection of S-hPAP (250 mU). Paired $t$ tests were used to compare responses within each genotype to BL (black asterisks) and between genotypes (red asterisks); $n=10$ mice per genotype. $\boldsymbol{D}$, Inset, Detailed time course to determine onset of antinociception. $\boldsymbol{E}, \boldsymbol{F}$, Mechanical $(\boldsymbol{E})$ and thermal $(\boldsymbol{F})$ sensitivity of WT and Trpv $1^{-1-}$ mice before (BL) and after injection of CFA into one hindpaw. One day later, the indicated mice were injected intrathecally with S-hPAP (250 mU) or heat-inactivated S-hPAP $(0 \mathrm{mU})$. CFA-injected and noninjected (control) hindpaws were tested. Paired $t$ tests were used to compare responses at each time point between WT mice and Trpv $1-1-$ mice injected with S-hPAP (red asterisks); $n=8$ mice per group; paired $t$ test, ${ }^{*} p<0.05,{ }^{* *} p<0.005,{ }^{* * *} p<0.0005$. All data are presented as means \pm SEM.

deplete intracellular calcium stores (supplemental Fig. S2C, available at www.jneurosci.org as supplemental material).

TRPV1 is also modulated by PIP $_{2}$ (Prescott and Julius, 2003; Liu et al., 2005; Stein et al., 2006; Lishko et al., 2007; Lukacs et al., 2007; Klein et al., 2008; Rohacs et al., 2008; Yao and Qin, 2009). At high capsaicin concentrations $(\geq 1 \mu \mathrm{M})$ and in the presence of extracellular calcium, $\mathrm{PIP}_{2}$ is required for TRPV1 channel activity, whereas depletion of $\mathrm{PIP}_{2}$ desensitizes the channel. This requirement for $\mathrm{PIP}_{2}$ suggested TM-PAP might inhibit TRPV1 by reducing cellular levels of $\mathrm{PIP}_{2}$ through sustained $\mathrm{A}_{1} \mathrm{R}$ activation.

To test this possibility, we quantified the levels of $\mathrm{PIP}_{2}$ in cells using the biosensor PLC $\delta$-PH-GFP (Várnai and Balla, 1998). When $\mathrm{PIP}_{2}$ levels are high, PLC $\delta$-PH-GFP is primarily localized to the PM. When $\mathrm{PIP}_{2}$ levels are reduced, PLC $\delta$-PH-GFP translocates from the membrane to the cytosol. This translocation can be quantified by measuring the GFP signal intensity on the PM relative to the cytosol (expressed as the ratio $\mathrm{PM} /$ cytosol). We used HEK293 cells for these experiments because this biosensor was difficult to visualize in Rat1 fibroblasts (although we reproduced our key finding in Rat1 cells) (supplemental Fig. S3, available at www.jneurosci.org as supplemental material).

In HEK293 cells expressing only PLC $\delta$-PH-GFP, the majority of the GFP signal was in the PM, giving a PM/cytosol ratio of $3.43 \pm 0.35$ (Fig. $2 A, E$ ). In contrast, PLC $\delta$-PH-GFP was redistributed to the cytosol in cells cotransfected with TM-PAP or $\mathrm{PLC} \beta 3(\mathrm{PM} /$ cytosol ratio of $1.60 \pm 0.06$ and $1.70 \pm 0.9$, respec- tively) (Fig. $2 B, E$ ). This finding suggested TM-PAP and PLC $\beta 3$ depleted $\mathrm{PIP}_{2}$ to a similar extent when expressed for an extended ( $\sim 24 \mathrm{~h}$ ) time period. Importantly, the $\mathrm{A}_{1} \mathrm{R}$ antagonist CPX and the PLC inhibitor U73122 blocked the TM-PAP-mediated redistribution of PLC $\delta$-PH-GFP to the cytosol (Fig. 2C,E), suggesting

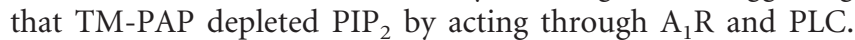
Additionally, the TM-PAP- and PLC $\beta 3$-mediated redistribution of PLC $\delta$-PH-GFP was blocked by overexpressing phosphatidylinositol-4-phosphate-5-kinase (PIPK) (Fig. 2D,E). PIPK increases $\mathrm{PIP}_{2}$ levels in transfected cells (Lin et al., 2005; Milosevic et al., 2005), suggesting TM-PAP and PLC $\beta 3$ altered PLC $\delta$-PHGFP membrane localization by depleting $\mathrm{PIP}_{2}$.

TM-PAP reduces TRPV1 activity by depleting PIP $_{2}$

Next, we genetically manipulated $\mathrm{PIP}_{2}$ levels to determine whether increasing or decreasing $\mathrm{PIP}_{2}$ affected capsaicin-evoked calcium responses. Both TM-PAP and PLC $\beta 3$ deplete $\mathrm{PIP}_{2}$ to a similar extent (Fig. 2 E), but only PLC $\beta 3$ hydrolyzes $\mathrm{PIP}_{2}$ directly. Likewise, both TM-PAP and PLC $\beta 3$ reduced capsaicin-evoked calcium responses to a similar extent (Fig. $2 F$ ), suggesting indirect or direct depletion of $\mathrm{PIP}_{2}$ was sufficient to reduce TRPV1 activity. Conversely, increasing $\mathrm{PIP}_{2}$ levels by overexpressing PIPK (which regenerates PIP $_{2}$ ) blocked TM-PAP and PLC 33 from inhibiting capsaicin-evoked calcium responses (Fig. $2 F$ ). These findings suggested signaling through TRPV1 was reduced as a direct result of $\mathrm{PIP}_{2}$ depletion, consistent with the findings of 
others using cultured cells (Liu et al., 2005; Stein et al., 2006; Lishko et al., 2007; Lukacs et al., 2007; Klein et al., 2008; Rohacs et al., 2008; Yao and Qin, 2009). In addition, TM-PAP did not affect the capsaicin-evoked calcium response in cells expressing TRPV1 142 (777-820) (data not shown), a TRPV1 mutant that is missing a putative $\mathrm{PIP}_{2}$ binding domain (Prescott and Julius, 2003; Kwon et al., 2007; Kim et al., 2008). Together, these data show that TM-PAP reduces TRPV1 activity in vitro through sustained activation of $A_{1} R$ and subsequent depletion of $\mathrm{PIP}_{2}$.

\section{$\mathrm{PAP}$ regulates $\mathrm{PIP}_{2}$ levels in vivo}

Since PAP regulated $\mathrm{PIP}_{2}$ levels in cultured cells, we hypothesized PAP might also regulate $\mathrm{PIP}_{2}$ levels in vivo. To test this hypothesis, we measured $\mathrm{PIP}_{2}$ levels in L3-L6 DRGs from WT mice that were injected (intrathecally) with vehicle or S-hPAP. We collected DRGs $1 \mathrm{~d}$ after injections because S-hPAP has maximal $\mathrm{A}_{1} \mathrm{R}$-dependent antinociceptive effects at this time (Zylka et al., 2008). Injection of S-hPAP significantly reduced $\mathrm{PIP}_{2}$ levels by $40 \pm 9 \%$ (Fig. $3 A$ ), and this reduction was dependent on $\mathrm{A}_{1} \mathrm{R}$ activation [as evidenced by the observation that $\mathrm{PIP}_{2}$ levels in L3-L6 DRGs were not significantly different in $A_{1} R^{-1-}$ mice injected (intrathecally) $1 \mathrm{~d}$ earlier with $250 \mathrm{mU}$ of S-hPAP $(250 \mathrm{mU})$ relative to heat-inactivated S-hPAP (0 mU); $159.6 \pm 23.5 \mathrm{pmol} / \mathrm{mg}$ DRG vs $174.4 \pm 28.0 \mathrm{pmol} / \mathrm{mg}$ DRG, respectively; $n=4$ mice per condition]. Conversely, $\mathrm{PIP}_{2}$ levels were elevated by $89 \pm 23 \%$ in DRGs from $\mathrm{Pap}^{-1-}$ mice (Fig. 3A). Together, these data suggest $\mathrm{PIP}_{2}$ levels are inversely related to the amount of PAP ectonucleotidase activity and $\mathrm{A}_{1} \mathrm{R}$ stimulation.

Since our cell-based data suggested that PAP depleted PIP $_{2}$ by activating PLC, we next evaluated whether the thermal antinociceptive effect of S-hPAP could be blocked using the PLC inhibitor U73122. This inhibitor was previously injected intrathecally (at $5.4 \mathrm{nmol}$ ) to block PLC activation by a $\delta$-opioid receptor ligand (Narita et al., 2000). Indeed, intrathecal injection of U73122 at the same dose transiently and completely blocked the thermal antinociceptive effect of S-hPAP, providing evidence that S-hPAP acted through PLC to reduce thermal sensitivity in vivo (Fig. $3 B, C$ ). Importantly, the $5.4 \mathrm{nmol}$ dose had no effect on thermal sensitivity when injected alone (Fig. $3 B, C$ ) (Narita et al., 2000). However, a higher U73122 dose (12.5 nmol) transiently enhanced thermal sensitivity (supplemental Fig. S4, available at www.jneurosci.org as supplemental material). Since strong PLC inhibition would be predicted to elevate $\mathrm{PIP}_{2}$ levels, this latter result suggests that the $\mathrm{PLC} / \mathrm{PIP}_{2}$ pathway tonically modulates thermal thresholds.

To directly assess whether S-hPAP reduced thermal sensitivity by depleting $\mathrm{PIP}_{2}$, we transiently replenished $\mathrm{PIP}_{2}$ in lumbar DRGs using a $\mathrm{PIP}_{2}$ shuttle (Ozaki et al., 2000). We found that injection (intrathecally) of $\mathrm{PIP}_{2}$ (complexed with carrier) transiently $\left(2 \mathrm{~h}\right.$ ) elevated $\mathrm{PIP}_{2}$ levels well above normal levels in lumpresented as means \pm SEM.
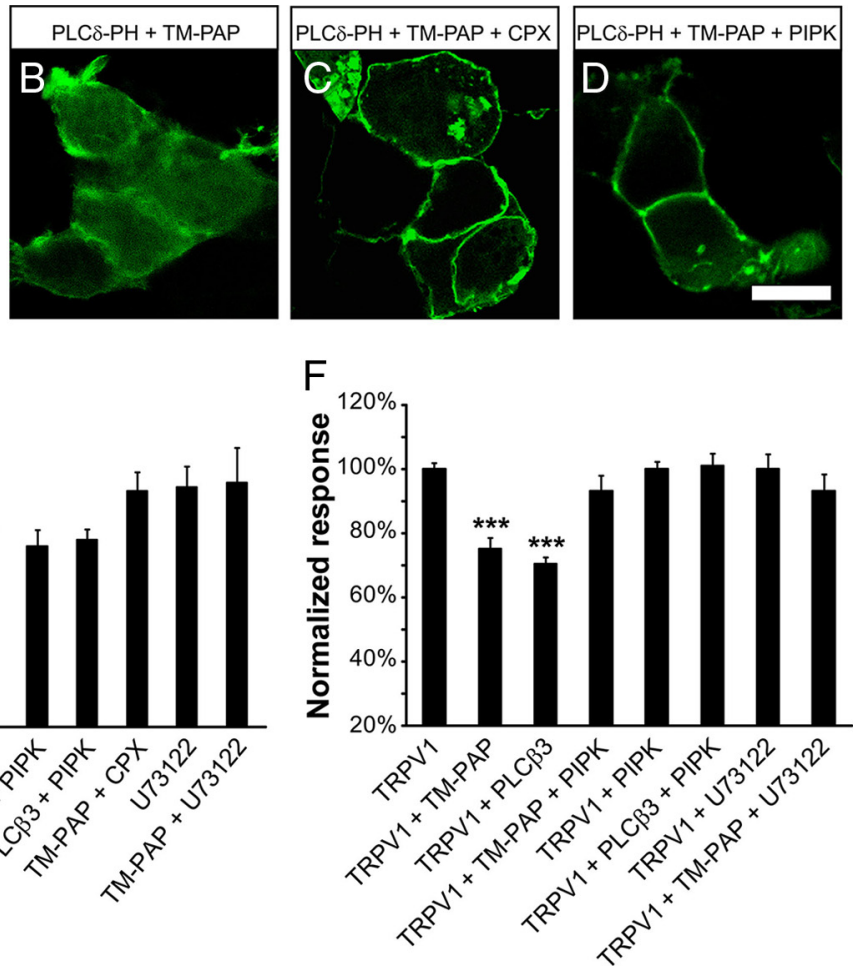

Figure 2. TM-PAP reduces capsaicin-evoked calcium responses by decreasing $\mathrm{PIP}_{2}$. $\boldsymbol{A}-\boldsymbol{D}$, Subcellular localization of the $\mathrm{PIP}_{2}$ biosensor PLC $\delta$-PH-EGFP (PLC $\delta$-PH) in HEK293 cells, imaged by confocal microscopy. PLC $\delta$-PH alone $(\boldsymbol{A})$, cotransfected with and expressed as a ratio; $n=30-70$ cells per condition. $F$, Normalized capsaicin $(1 \mu \mathrm{m})$-evoked calcium responses in Rat1

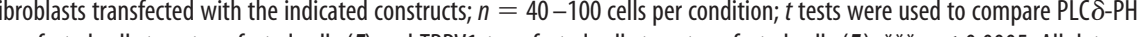

bar DRGs (Fig. 3D), whereas injection of carrier alone (the control) had no effect (based on the observation that PIP $_{2}$ levels in L3-L6 DRGs were not significantly different in WT mice relative to WT mice injected intrathecally with Car; $112.0 \pm 14.6$ $\mathrm{pmol} / \mathrm{mg}$ DRG vs $102.5 \pm 10.5 \mathrm{pmol} / \mathrm{mg}$ DRG, respectively; $n=$ 4 mice per condition). Strikingly, intrathecal injection of $\mathrm{PIP}_{2}$ (complexed with carrier) also transiently $(2 \mathrm{~h})$ reversed S-hPAPmediated thermal antinociception, whereas carrier alone had no effect (Fig. 3E,F). The fact that behavior was significantly altered only during the time at which $\mathrm{PIP}_{2}$ was significantly elevated makes it unlikely these effects on thermal sensitivity were a coincidence. Instead, these results strongly suggest that PAP inhibits thermal sensitivity as a direct result of $\mathrm{PIP}_{2}$ depletion. Moreover, control animals injected with $\mathrm{PIP}_{2}$ displayed transient thermal hyperalgesia, suggesting thermal sensitivity can be enhanced when $\mathrm{PIP}_{2}$ levels are elevated above normal levels. The magnitude of this effect on thermal sensitivity in control animals was smaller (2.6 s) than in animals that were injected with $\mathrm{S}$-hPAP and $\mathrm{PIP}_{2}(4.0 \mathrm{~s})$. This argues that $\mathrm{PIP}_{2}$ replenishment was sufficient to block the thermal antinociceptive effect of S-hPAP independent of how $\mathrm{PIP}_{2}$ affects thermal sensitivity in control animals.

Together, our data strongly support a mechanism (Fig. 3G) in which (1) TM- and S-PAP function as ectonucleotidases that generate adenosine. Adenosine then stimulates (2) $\mathrm{A}_{1} \mathrm{R}$ in a sustained fashion, followed by (3) PLC activation and (4) $\mathrm{PIP}_{2}$ hydrolysis. (5) Sustained reductions in $\mathrm{PIP}_{2}$ levels decreased TRPV1 

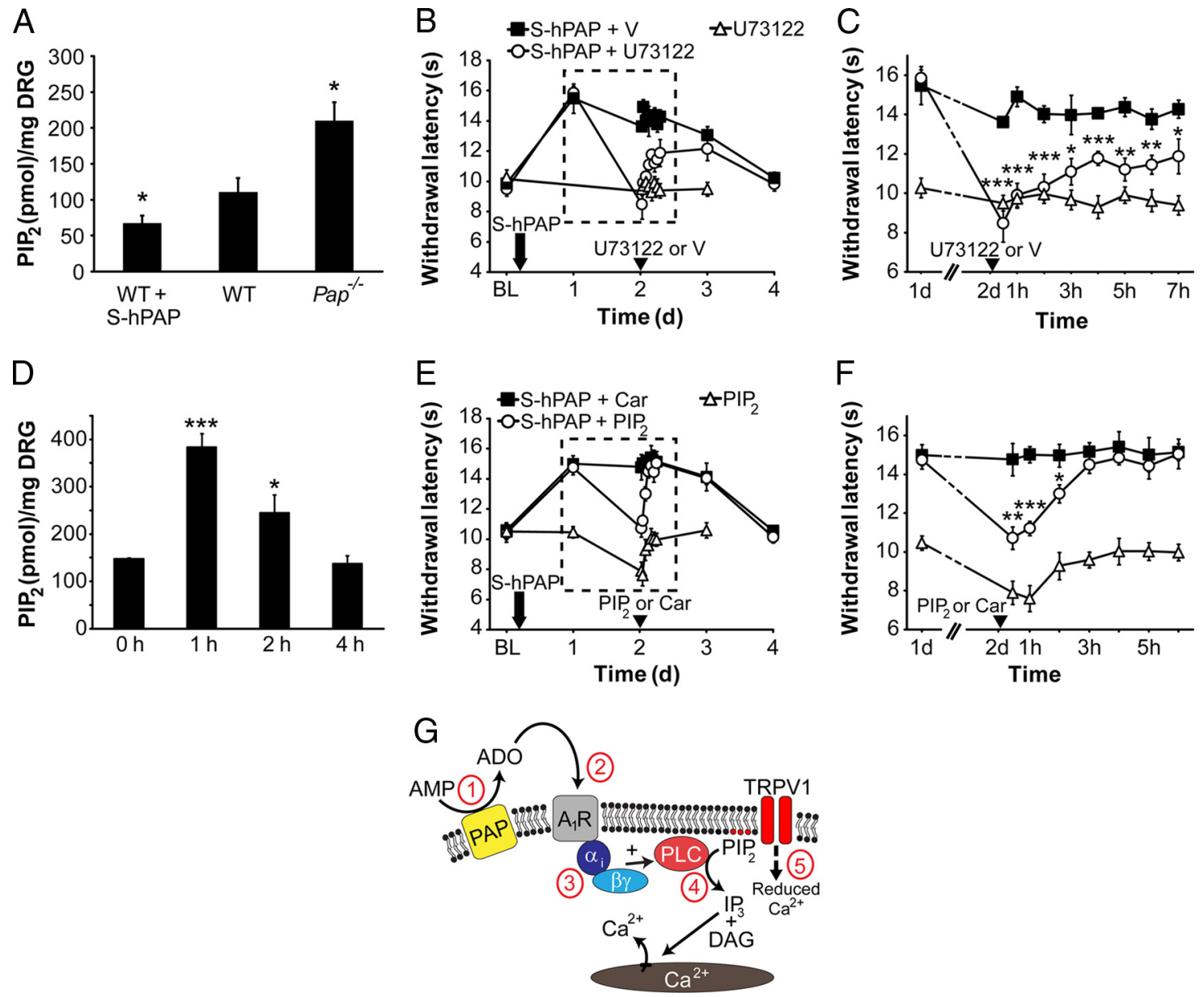

Figure 3. Manipulation of PIP 2 levels in vivo. A, PIP 2 levels in L3-L6DRGs were quantified in WT mice, Pap ${ }^{-1-}$ mice, or WT mice injected (intrathecally) 1 d earlier with 250 mU of S-hPAP. Values were compared with WT by paired $t$ test; $n=3$ mice per condition. $\boldsymbol{B}, \boldsymbol{C}$, The hindpaws of WT mice were tested for noxious thermal sensitivity before [baseline (BL)] and after intrathecal injection of S-hPAP $(250 \mathrm{mU})$ or saline. Two days later, the indicated mice were injected intrathecally with either U73122 ( $5.4 \mathrm{nmol})$ or vehicle (V) and thermal sensitivity was measured every hour for the first $7 \mathrm{~h}$ as well as for the next $2 \mathrm{~d}$. Data in C are from the boxed area in $\boldsymbol{B}$. Mice injected with U73122 were compared with vehicle-injected mice at each time point by paired $t$ test; $n=8$ mice per group. $D, P_{2}$ in L3-L6 DRGs was quantified in WT mice at the given time points after intrathecal injection with $\mathrm{PIP}_{2}(3 \mathrm{nmol})$ plus carrier. Mice from later time points were compared with time 0 values by paired $t$ test; $n=4$ mice per condition. $\boldsymbol{E}, \boldsymbol{F}$, The hindpaws of WT mice were tested for noxious thermal sensitivity before (BL) and after intrathecal injection of S-hPAP ( $250 \mathrm{mU}$ ) or saline. Two days later, the indicated mice were injected intrathecally with carrier (Car) or PIP 2 ( $3 \mathrm{nmol}$ ) plus carrier, and then thermal sensitivity was measured every hour for the first $6 \mathrm{~h}$ after injection as well as for the next $2 \mathrm{~d}$. Data in $\boldsymbol{F}$ are from the boxed area in $\boldsymbol{E}$. Mice injected with PIP 2 after S-hPAP were compared with vehicle-injected mice at each time point by paired $t$ test. $\mathbf{G}$, Model showing how PAP interferes with TRPV1 channel activity (see text for details). ${ }^{*} p<0.05,{ }^{* *} p<0.005,{ }^{* * *} p<0.0005$. All data are presented as means \pm SEM.

activity and decreased noxious thermal sensitivity. In addition, our data suggest $\mathrm{PIP}_{2}$ levels are regulated by tonic ectonucleotidase-dependent adenosine production and $\mathrm{A}_{1} \mathrm{R}$ activation.

\section{PAP inhibits pronociceptive LPA receptor signaling by reducing $\mathrm{PIP}_{2}$ levels}

Diverse chemicals are released after injury and inflammation and sensitize nociceptive neurons, in many cases, by activating pronociceptive GPCRs (Hucho and Levine, 2007; Basbaum et al., 2009). Since many pronociceptive receptors signal through PLC (and hence require $\mathrm{PIP}_{2}$ for signaling), we hypothesized that PAP might reduce signaling through pronociceptive receptors via sustained activation of $\mathrm{A}_{1} \mathrm{R}$ and $\mathrm{PIP}_{2}$ depletion. Such a mechanism could have important physiological implications because reduced signaling through pronociceptive receptors would be predicted to reduce nociceptive sensitization, a key symptom of chronic pain. LPA is a pronociceptive ligand that sensitizes nociceptive neurons, causes long-lasting $(>7 \mathrm{~d})$ sensitization in vivo (including thermal hyperalgesia and mechanical allodynia), and is implicated in neuropathic pain mechanisms (Elmes et al., 2004;
Inoue et al., 2004; Park and Vasko, 2005). In addition, LPA receptors are coupled to $\mathrm{G} \alpha_{\mathrm{q} / 11}$-proteins and signal through PLC in many cell types, including Rat1 fibroblasts (which endogenously express LPA receptors) (Mills and Moolenaar, 2003; Kelley et al., 2006).

Using Rat1 fibroblasts, we found that the amplitude and duration of LPA-evoked calcium responses were significantly reduced in cells expressing TM-PAP relative to untransfected cells in the same field of view (Fig. 4A,D). This "PAP effect" was species-conserved as cells transfected with TM-hPAP (human TM-PAP) were also less responsive to LPA stimulation (Fig. $4 B, D)$. In contrast, the LPA-evoked calcium response was not reduced in cells transfected with the catalytically inactive TM$\operatorname{PAP}(\mathrm{H} 12 \mathrm{~A})$ mutant (Fig. 4C,D).

To determine whether TM-PAP inhibited LPA-evoked signaling by generating adenosine and activating $A_{1} R$, we assessed whether PTX (an inhibitor of $\mathrm{G} \alpha_{\mathrm{i} / \mathrm{o}}$-coupled receptors) or adenosine receptor antagonists could block the effect of TM-PAP on LPA-evoked signaling. We found that PTX completely blocked the PAP effect, as evidenced by no significant differences between 
untransfected cells and TM-PAP plus PTX-treated cells (Fig. 4D). Additionally, the PAP effect was blocked by the $A_{1} / A_{2 B}$ adenosine receptor antagonist caffeine (Caff) and by two different $\mathrm{A}_{1} \mathrm{R}$-selective antagonists: CPT and CPX (Fig. 4D). In contrast, selective antagonists of all other adenosine receptors $\left(\mathrm{A}_{2 \mathrm{~A}} \mathrm{R}, \mathrm{SCH}\right.$ 58261; $\mathrm{A}_{2 \mathrm{~B}} \mathrm{R}, \mathrm{MRS} 1754 ; \mathrm{A}_{3} \mathrm{R}$, MRS 1523) did not block the PAP effect (data not shown).

Next, we evaluated whether increasing or decreasing $\mathrm{PIP}_{2}$ affected LPA-evoked calcium responses in our cell-based assay. We found that both TM-PAP and PLC $\beta 3$ reduced LPA-evoked calcium responses to a similar extent (Fig. 4D), suggesting indirect or direct depletion of $\mathrm{PIP}_{2}$ was sufficient to reduce signaling. This is consistent with a previous study showing that LPA-evoked $\mathrm{Ca}^{2+}$ responses were reduced to baseline levels when $\mathrm{PIP}_{2}$ was depleted using an inducible $\mathrm{PIP}_{2}$ phosphatase (Várnai et al., 2006). Conversely, increasing $\mathrm{PIP}_{2}$ levels by overexpressing PIPK blocked the TM-PAP- and PLC $\beta 3$ mediated reduction in LPA-evoked calcium responses (Fig. 4D). Moreover, restoring $\mathrm{PIP}_{2}$ levels with the $\mathrm{PIP}_{2}$ shuttle blocked the inhibitory effect of TM-PAP (supplemental Fig. S5, available at www. jneurosci.org as supplemental material). These experiments provide complementary support that TM-PAP inhibits LPA receptor signaling as a direct result of $\mathrm{PIP}_{2}$ depletion. The inhibitory effect of TMPAP was also blocked with the PLC inhibitor U73122 (Fig. 4D), further indicating that TM-PAP acts via PLC to deplete PIP 2 . As expected, the magnitude of the LPAevoked $\mathrm{Ca}^{2+}$ influx was smaller in all cells when PLC was inhibited. Last, TM-PAP did not reduce LPA signaling by acting through other pathways that are downstream of $A_{1} R$, including $G \alpha_{\mathrm{i} / \mathrm{o}}$-mediated inhibition of PKA or DAG-mediated PKC activation (data not shown).

\section{TM-PAP reduces signaling through several} pronociceptive GPCRs

Since many pronociceptive receptors are $\mathrm{G} \alpha_{\mathrm{q} / 11}$-coupled and signal via PLC, we hypothesized that TM-PAP might reduce signaling through additional pronociceptive receptors, including purinergic receptors (using the ligand ATP), protease-activated receptors (using the ligand Thr), and BK receptors. Importantly, activation of these receptors evokes transient calcium responses in Rat 1 cells and causes nociceptive sensitization in vivo (Kelley et al., 2006; Wang et al., 2006; Burnstock, 2007; Sawynok, 2007; Dale and Vergnolle, 2008). Strikingly, calcium responses induced by all three ligands were reduced in TM-PAP-transfected cells relative to untransfected cells, and these reductions were blocked by the $\mathrm{A}_{1} \mathrm{R}$ antagonist CPX and by overexpressing PIPK (Fig. $4 E$ ).

Collectively, our data further support a mechanism (Fig. $4 F$ ) in which (1) PAP functions as an ectonucleotidase to generate adenosine over a sustained time period. (2) Adenosine then stim- ulates $\mathrm{A}_{1} \mathrm{R}$ followed by (3) PLC activation and (4) PIP $\mathrm{P}_{2}$ hydrolysis. With less $\mathrm{PIP}_{2}$ available for (5) $\mathrm{G} \alpha_{\mathrm{q} / 11} / \mathrm{PLC}$-mediated receptor signaling, less $\mathrm{IP}_{3}$ (and DAG) is generated after receptor stimulation, resulting in smaller pronociceptive ligandevoked calcium responses.

\section{PAP enduringly blocks LPA- and ATP-induced hyperalgesia and allodynia}

Since PAP reduced pronociceptive receptor signaling in Rat 1 cells by depleting $\mathrm{PIP}_{2}$, we hypothesized that PAP might also reduce signaling through pronociceptive receptors in vivo. To test this possibility, we took advantage of the fact that both LPA and ATP produce long-lasting $(>7 \mathrm{~d})$ thermal hyperalgesia and mechanical allodynia when injected intrathecally (Inoue et al., 2004; Nakagawa et al., 2007). This is longer than the $3 \mathrm{~d}$ antihyperalgesic and antiallodynic effects of S-hPAP (Zylka et al., 2008). Thus, by injecting S-hPAP $1 \mathrm{~d}$ before ATP or LPA, we could ascertain whether S-hPAP reduced initiation of LPA- or ATP-evoked signaling by quantifying hyperalgesia and allodynia on days 4 and 8 (i.e., after the $3 \mathrm{~d}$ antinociceptive effects of PAP wore off). 
A

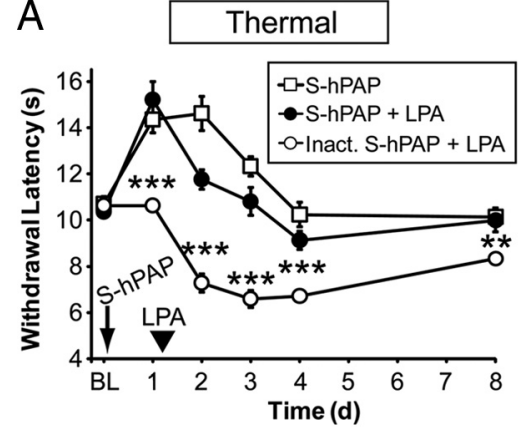

C

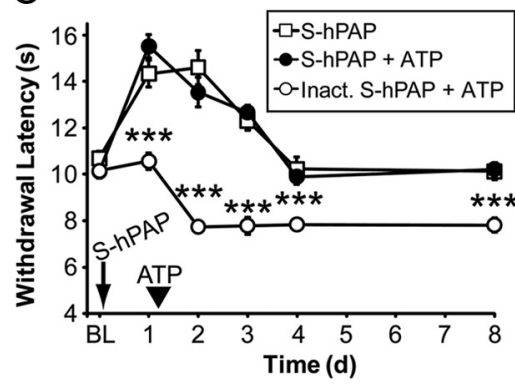

B

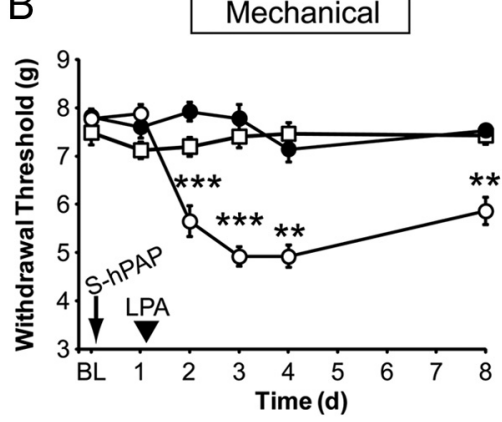

$\mathrm{D}$

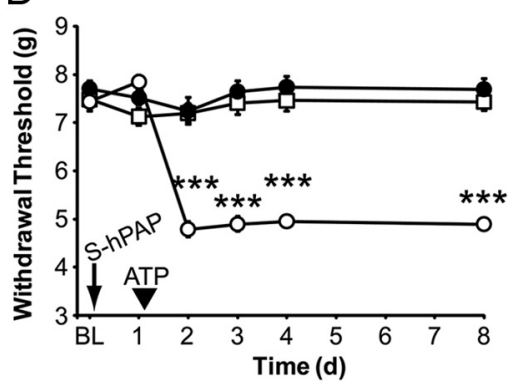

Figure 5. Secretory PAP inhibits pronociceptive receptor signaling in vivo. $\boldsymbol{A}-\boldsymbol{D}$, The hindpaws of WT mice ( $n=10$ per group) were tested for noxious thermal and mechanical sensitivity before [baseline (BL)] and after intrathecal injection of S-hPAP (250 $\mathrm{mU})$ or heat-inactivated S-hPAP $(0 \mathrm{mU})$. One day later, mice were injected intrathecally with $5 \mathrm{nmol}$ of LPA $(\boldsymbol{A}, \boldsymbol{B})$ or $100 \mathrm{nmol}$ of $\operatorname{ATP}(\boldsymbol{C}, \boldsymbol{D})$. Paired $t$ tests were used to compare responses at each time point between mice injected with S-hPAP plus LPA to mice injected with inactive S-hPAP plus LPA. The S-hPAP data (open squares) shown in $\boldsymbol{A}-\boldsymbol{D}$ are from a different experiment with WT mice and are plotted here to provide a visual, not statistical, reference for comparison. ${ }^{* *} p<0.005,{ }^{* * *} p<0.0005$. All data are presented as means \pm SEM.

First, we measured baseline (BL) thermal and mechanical sensitivity in two groups of WT mice. Next, we injected S-hPAP (intrathecally) into one of the groups and heat-inactivated S-hPAP (control; catalytically dead) into the other group (Fig. 5) (a third group of S-hPAP-injected mice from a different experiment is shown, to provide a visual reference for how S-hPAP typically affects naive mice). One day later, S-hPAP increased paw withdrawal latency to the noxious thermal stimulus but had no effect on mechanical sensitivity, whereas inactive S-hPAP had no effects on thermal or mechanical sensitivity (Fig. 5). These results were expected (Zylka et al., 2008) and confirmed that mice received an active or inactive dose of S-hPAP. After taking these measurements, we injected (intrathecally) either $5 \mathrm{nmol}$ of LPA (Fig. $5 A, B$ ) or $100 \mathrm{nmol}$ of ATP (Fig. $5 C, D$ ). These doses produce maximal sensitization in animals (Inoue et al., 2004; Nakagawa et al., 2007). Both pronociceptive compounds produced longlasting thermal hyperalgesia and mechanical allodynia in the control (inactive S-hPAP-injected) mice. In contrast, mice injected with S-hPAP and then LPA/ATP were significantly different from controls at all times after LPA/ATP injections and did not develop thermal hyperalgesia or mechanical allodynia, as evidenced by latencies and thresholds that were at or near baseline levels on days 4 and 8 . These data suggest that PAP, an enzyme that reduces $\mathrm{PIP}_{2}$ levels in vivo (Fig. $3 \mathrm{~A}$ ), blocked physiologically relevant signaling and sensitization through two distinct pronociceptive receptors. Conversely, thermal hyperalgesia and mechanical allodynia were significantly and enduringly enhanced after LPA or ATP injection in $\mathrm{Pap}^{-1-}$ mice (Fig. 6) - that is, mice that have elevated levels of $\mathrm{PIP}_{2}$ in lumbar DRGs (Fig. $3 A$ ).
PAP preemptively inhibits sensitization caused by inflammation and nerve injury

Although LPA and ATP produce longlasting sensitization in vivo, injection of these chemicals may not fully model the sensitization and pathology that is associated with chronic pain conditions. To determine whether reducing $\mathrm{PIP}_{2}$ levels with S-hPAP had a more generalized effect on the signals that initiate pain sensitization, we tested S-hPAP in the CFA model of inflammatory pain and in the SNI model of neuropathic pain. Strikingly, intrathecal injection of S-hPAP before CFAinduced inflammation nearly eliminated thermal hyperalgesia and significantly reduced mechanical allodynia for the duration of the experiment compared with controls injected with inactive S-hPAP (Fig. $7 A, B$ ). These preemptive antinociceptive effects of S-hPAP were dependent on $A_{1} R$ activation (supplemental Fig. S6, available at www.jneurosci.org as supplemental material). In addition, intrathecal injection of S-hPAP before nerve injury eliminated thermal hyperalgesia and significantly reduced mechanical allodynia for the duration of the experiment compared with mice injected with inactive S-hPAP (Fig. 7C,D). Collectively, these findings indicate that S-hPAP enduringly blocks sensitization in two chronic pain models when injected before inflammation/injury.

\section{Direct elevation of $\mathrm{PIP}_{2}$ in DRGs enhances nociceptive sensitization}

Since PIP 2 levels in DRGs were indirectly elevated and sensitization was enhanced in $P a p^{-1-}$ mice [data above and in the study by Zylka et al. (2008)], we next sought to determine whether direct elevation of $\mathrm{PIP}_{2}$ in DRGs could enhance sensitization. To accomplish this, we coinjected (intrathecally) WT mice with LPA plus Car (the control) or LPA plus PIP $_{2}$ plus Car, and then measured noxious thermal and mechanical sensitivity for several days. Importantly, there is a critical window of $3 \mathrm{~h}$ over which LPA (injected intrathecally) signals to produce nociceptive sensitization in mice (Ma et al., 2009). Since $\mathrm{PIP}_{2}$ levels are only elevated in DRGs for $2 \mathrm{~h}$ after injection (Fig. 3D), these coinjection experiments allowed us to elevate PIP ${ }_{2}$ levels only when LPA receptors were active in vivo. Strikingly, when $\mathrm{PIP}_{2}$ levels were elevated coincident with LPA receptor activation, thermal hyperalgesia and mechanical allodynia were significantly and reproducibly enhanced for the duration of the experiment (Fig. 8A,B). In contrast, injection of Car alone or $\mathrm{PIP}_{2}$ plus Car in the absence of a pronociceptive stimulus had no long-term effects on thermal or mechanical sensitivity (Fig. 8C,D). And injection of Car alone or $\mathrm{PIP}_{2}$ plus Car did not sensitize mice when injected $3 \mathrm{~d}$ after LPA was injected (i.e., well past the $3 \mathrm{~h}$ critical window for LPA receptor signaling) (Fig. $8 E, F)$. In this same experiment, $\mathrm{PIP}_{2}$ plus Car (but not Car alone) caused a transient ( $2 \mathrm{~h}$ ) enhancement in thermal sensitivity (data not shown), thus reproducing our findings above (Fig. $3 E, F$ ) and confirming that these $\mathrm{PIP}_{2}$ injections were successful and had the capacity to affect 
behavior. Together, these experiments strongly argue that $\mathrm{PIP}_{2}$ levels must be elevated in DRGs at the time of pronociceptive receptor activation to enhance thermal and mechanical sensitization.

Last, we sought to determine whether direct elevation of $\mathrm{PIP}_{2}$ could enhance thermal and mechanical sensitization caused by CFA. For this experiment, all mice were injected intrathecally with Car or $\mathrm{PIP}_{2}$ plus Car immediately before injecting CFA into one hindpaw. CFA sensitizes nociceptors through the release of an "inflammatory soup" composed of diverse pronociceptive ligands (Basbaum et al., 2009). Since this soup could activate pronociceptive receptors for an extended period of time (and since $\mathrm{PIP}_{2}$ is only elevated for $2 \mathrm{~h}$ after a single injection), we reinjected (intrathecally) all mice $2 \mathrm{~h}$ later with $\mathrm{PIP}_{2}$ plus Car (or Car alone). This ensured that $\mathrm{PIP}_{2}$ levels remained elevated while CFA "initiated" sensitization. Strikingly, CFA-induced thermal hyperalgesia and mechanical allodynia were significantly enhanced for the duration of the experiment when $\mathrm{PIP}_{2}$ levels were transiently elevated (Fig. 8G,H) [compare the inflamed paw of $\mathrm{PIP}_{2}$ plus Carinjected mice to the inflamed paw of Car alone (control) mice]. In contrast, thermal and mechanical responses were not altered in the contralateral (uninflamed) paws of mice injected with $\mathrm{PIP}_{2}$ plus Car (Fig. 8G,H), further demonstrating that acute elevation of $\mathrm{PIP}_{2}$ does not sensitize mice in the absence of a pronociceptive stimulus.

\section{Discussion}

In our effort to determine how PAP regulated nociception at a mechanistic level, we found that sustained $A_{1} R$ activation reduced the levels of $\mathrm{PIP}_{2}$ in cells and in DRGs. This reduction in $\mathrm{PIP}_{2}$ reduced noxious thermal sensitivity, in part through inhibition of TRPV1. And this reduction in $\mathrm{PIP}_{2}$ enduringly reduced nociceptive sensitization to thermal and mechanical stimuli.

\section{PAP regulates thermosensation through TRPV1}

Numerous studies found that TRPV1 can be modulated by $\mathrm{PIP}_{2}$ in vitro (for review, see Rohacs et al., 2008). At low capsaicin concentrations and in the absence of extracellular calcium, $\mathrm{PIP}_{2}$ partially inhibits TRPV1 (Prescott and Julius, 2003). In contrast, at high capsaicin concentrations and in the presence of extracellular calcium, $\mathrm{PIP}_{2}$ is required for TRPV1 activity (Liu et al., 2005; Stein et al., 2006; Lishko et al., 2007; Lukacs et al., 2007; Klein et al., 2008; Yao and Qin, 2009).
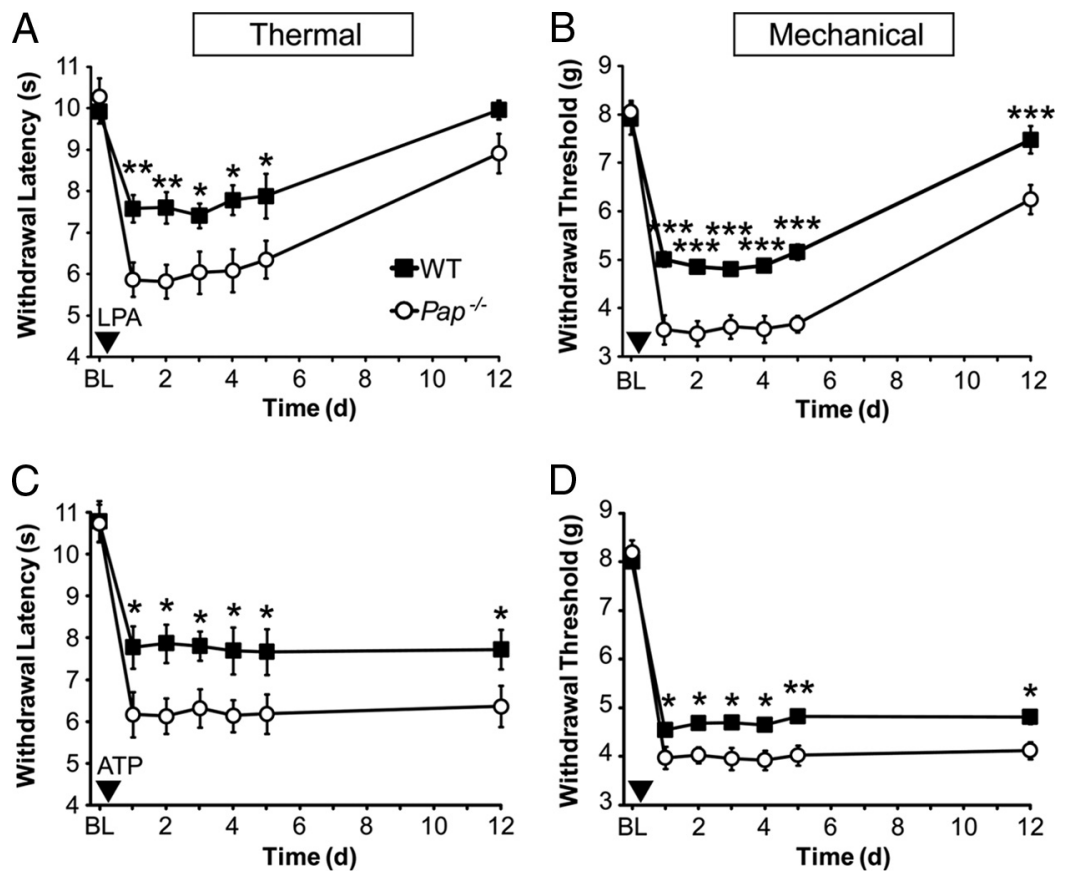

Figure 6. Pap ${ }^{-1-}$ mice show enhanced LPA- and ATP-induced thermal hyperalgesia and mechanical allodynia. $A-D$, The hindpaws of WT and $P a p^{-1-}$ mice were tested for noxious thermal and mechanical sensitivity before [baseline (BL)] and after intrathecal injection of LPA $(5 \mathrm{nmol})(\boldsymbol{A}, \boldsymbol{B})$ or ATP $(100 \mathrm{nmol})(\boldsymbol{C}, \boldsymbol{D}) ; n=10$ mice per genotype. Pap ${ }^{-1-}$ mice developed significantly greater thermal hyperalgesia ( $p<0.0001$ by two-way ANOVA) and mechanical allodynia ( $p<0.0001$ by two-way ANOVA) in response to intrathecal LPA or ATP. Post hoc paired $t$ tests were used to compare responses at each time point between genotypes. ${ }^{*} p<0.05,{ }^{* *} p<0.005,{ }^{* * *} p<0.0005$. All data are presented as means \pm SEM.
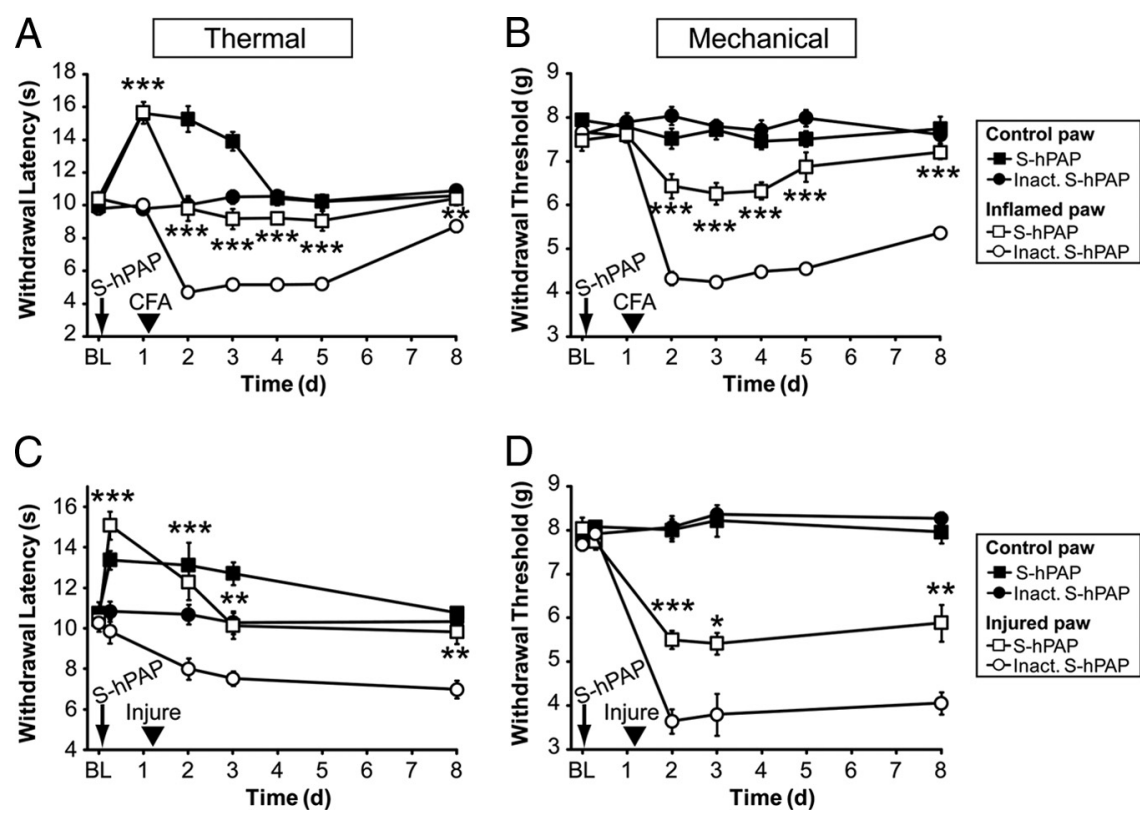

Figure 7. Secretory PAP partially blocks the initiation of inflammatory and neuropathic pain. $A-D$, The hindpaws of WT mice ( $n=10$ per group) were tested for noxious thermal and mechanical sensitivity before [baseline (BL)] and after intrathecal injection of S-hPAP $(250 \mathrm{mU})$ or heat-inactivated S-hPAP $(0 \mathrm{mU})$. One day later, CFA was injected into one hindpaw (CFA arrowhead) $(\boldsymbol{A}, \boldsymbol{B})$ or peripheral nerves were injured using the SNI model of neuropathic pain (Injure arrowhead) $(\boldsymbol{C}, \boldsymbol{D})$. Paired $t$ tests were used to compare responses at each time point between mice injected with S-hPAP (open square; injured paw) and those injected with inactive hPAP (open circles; injured paw). ${ }^{*} p<0.05,{ }^{* *} p<0.005,{ }^{* * *} p<0.0005$. All data are presented as means \pm SEM.

These contrasting in vitro results made it difficult to predict how alterations in the levels of PIP $_{2}$ might affect thermosensation in animals. In our present study, we found that PAP inhibited TRPV1 in cultured cells through sustained $A_{1} R$ activation and 

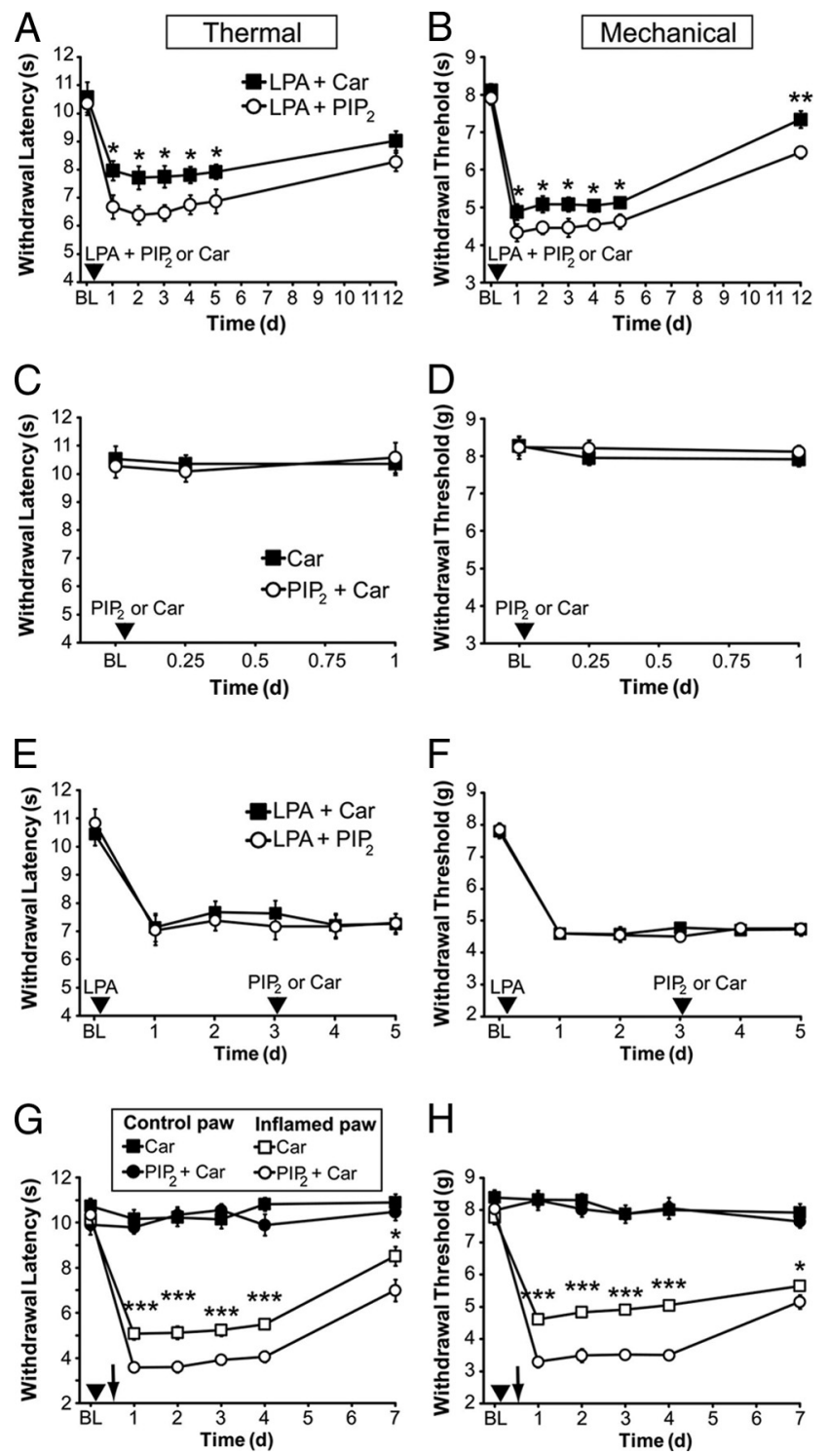

Figure 8. Increasing PIP levels at the time of LPA injection or inflammation enhances sensitization. $\boldsymbol{A}-\boldsymbol{D}$, One hindpaw of WT mice was tested for noxious thermal and mechanical sensitivity ( $n=10$ mice per group). After taking baseline (BL) measurements, mice were injected intrathecally with LPA ( $5 \mathrm{nmol})$ plus Car or LPA ( $5 \mathrm{nmol})$ plus PIP 2 ( $3 \mathrm{nmol})$ plus Car $(\boldsymbol{A}$, $\boldsymbol{B})$; Car or $\mathrm{PIP}_{2}(3 \mathrm{nmol})$ plus $\mathrm{Car}(\boldsymbol{C}, \boldsymbol{D}) . \boldsymbol{E}, \boldsymbol{F}$, One hindpaw of WT mice was tested for noxious thermal and mechanical sensitivity ( $n=10$ mice per group). After taking BL measurements, mice were injected intrathecally with LPA (arrowhead; $5 \mathrm{nmol}$ ). Three days later, mice were injected intrathecally with Car or PIP 2 (3 nmol) plus Car (arrow). $\mathbf{G}, \boldsymbol{H}$, The hindpaws of WT mice were tested for noxious thermal and mechanical sensitivity. After taking BL measurements, mice were injected intrathecally with Car or $\mathrm{PIP}_{2}(3 \mathrm{nmol})$ plus Car, and then were immediately injected with CFA into one hindpaw (arrowhead). Two hours after CFA injection, mice were reinjected intrathecally with Car or $\mathrm{PIP}_{2}$ ( 3 nmol) plus Car (arrow). Inflamed and noninflamed (control) hindpaws were tested. For $\boldsymbol{A}-\boldsymbol{F}$, paired $t$ tests were used to compare groups at each time point. For $\boldsymbol{G}$ and $\boldsymbol{H}$, paired $t$ tests were used to compare responses at each time point between mice injected with Car (open circles; injured paw) and those injected with $\mathrm{PIP}_{2}$ plus Car (open squares; injured paw). ${ }^{*} p<0.05,{ }^{* *} p<0.005,{ }^{* * *} p<0.0005$. All data are presented as means \pm SEM.

PLC-mediated $\mathrm{PIP}_{2}$ depletion. Likewise, PAP inhibited thermosensation in mice through $\mathrm{A}_{1} \mathrm{R}$ activation (Zylka et al., 2008), PLC activation (Fig. $3 B, C$ ), and $\mathrm{A}_{1} \mathrm{R}$-dependent $\mathrm{PIP}_{2}$ depletion (Fig. $3 A$ and data above). Moreover, the inhibitory effect of PAP on thermosensation was partially dependent on TRPV1 activation (Fig. 1D). Conversely, thermosensation was modestly en- hanced when $\mathrm{PIP}_{2}$ levels were elevated in vivo (Fig. $3 E, F$ ). Together, our findings suggest that $\mathrm{PIP}_{2}$ facilitates thermosensation in vivo through TRPV1-dependent and independent mechanisms. Our findings are consistent with a study showing that TRPV1-dependent thermosensation was enhanced through interactions with PIRT, a $\mathrm{PIP}_{2}$-binding protein (Kim et al., 2008).

Pronociceptive GPCR activation can sensitize TRPV1 via PKC/PLC (Bhave et al., 2003; Huang et al., 2006). Since $A_{1} R$ is also coupled to PLC (Murthy and Makhlouf, 1995; Jacobson and Gao, 2006), this raises the question of why PAP inhibits TRPV1 following $A_{1} R$ activation, as we observed, instead of sensitizing TRPV1? This likely reflects differences in how pronociceptive GPCRs and $A_{1} R$ couple to downstream signaling pathways. Pronociceptive receptors, including LPA receptors, are coupled to PLC isoforms via $\mathrm{G} \alpha_{\mathrm{q} / 11^{-}}$and $\mathrm{G} \beta \gamma$-proteins. Stimulation of these receptors evokes transient PKC activation and large PLCdependent calcium responses that desensitize rapidly (Mills and Moolenaar, 2003; Kelley et al., 2006). In contrast, $A_{1} R$ is coupled to PLC isoforms exclusively via $G \beta \gamma$-proteins and $A_{1} R$ does not desensitize, at least when activated by ectonucleotidasegenerated adenosine. Specifically, we found that $A_{1} R$ does not desensitize when activated for a sustained $3 \mathrm{~d}$ time period by PAP (Zylka et al., 2008; Sowa et al., 2009) or on repeated injection of S-hPAP (data not shown). And importantly, the PLC inhibitor U73122 transiently inhibited PAP antinociception (Fig. $3 B, C$ ), arguing that PLC is active over this $3 \mathrm{~d}$ period. These data suggest that ectonucleotidase-dependent activation of $A_{1} R$ is sufficient to deplete $\mathrm{PIP}_{2}$ and inhibit TRPV1 but is not sufficient to activate PKC, sensitize TRPV1, or detectably elevate calcium levels. Indeed, we found that PAP did not inhibit TRPV1 through PKC (supplemental Fig. S2A, available at www.jneurosci.org as supplemental material) nor did PAP reduce intracellular $\left(\mathrm{IP}_{3}\right.$ sensitive) calcium stores (supplemental Fig. S2C, available at www.jneurosci.org as supplemental material). And acute stimulation with the $\mathrm{A}_{1} \mathrm{R}$ agonist $N^{6}$-cyclopentyladenosine ( $300 \mathrm{nM}$ ) did not evoke $\mathrm{Ca}^{2+}$ influx in cultured small-diameter DRG neurons from adult mice (E. McCoy and M. J. Zylka, unpublished data).

We found that most of the thermal antinociceptive effects of PAP were lost in Trpv1 $1^{-/-}$mice, whereas the mechanical antinociceptive effects of PAP were preserved (Fig. $1 D-F$ ). This dissociation suggests that most of the thermal antinociceptive effects of PAP were mediated through TRPV1, whereas the remaining thermal and mechanical antinociceptive effects of PAP were likely mediated by other $\mathrm{PIP}_{2}$-sensitive channels or proteins. Depletion of $\mathrm{PIP}_{2}$ generally reduces ion channel activity, including KCNQ, $\mathrm{P}_{2}$, and N-type calcium channels (Gamper et al., 2004; Suh and Hille, 2005; Bernier et al., 2008), all of which could affect nociception (Basbaum et al., 2009). In addition, PIP $_{2}$ depletion inhibits synaptic vesicle exocytosis (Di Paolo and De Camilli, 2006). Additional studies will be needed to determine whether additional antinociceptive effects of PAP are attributable to inhibition or modulation of other $\mathrm{PIP}_{2}$-sensitive channels, proteins, or mechanisms.

PIP $_{2}$ levels at the time of pronociceptive receptor activation enduringly regulate the magnitude of pain sensitization

We unexpectedly found that nociceptive sensitization could be enduringly altered by manipulating the levels of $\mathrm{PIP}_{2}$ at the time of stimulation/injury. This suggests that any manipulation, be it genetic or environmental, which alters $\mathrm{PIP}_{2}$ levels could have a lasting impact on nociceptive sensitization. Indeed, we found that thermal hyperalgesia and mechanical allodynia were endur- 
ingly enhanced only when $\mathrm{PIP}_{2}$ levels were elevated coincident with LPA receptor activation. $\mathrm{PIP}_{2}$ injection alone or $\mathrm{PIP}_{2}$ injection several days after LPA injection did not produce, enhance, or prevent sensitization. Direct elevation of $\mathrm{PIP}_{2}$ in DRGs also enhanced sensitization caused by peripheral injection of CFA, further supporting the physiological importance of $\mathrm{PIP}_{2}$ in nociceptive sensitization. Intriguingly, these findings also hint that $\mathrm{PIP}_{2}$ levels in DRGs regulate sensitization regardless of whether pain-producing stimuli are administered centrally (i.e., LPA) or peripherally (i.e., CFA).

Likewise, we found that sensitization could be enduringly altered by increasing or decreasing $\mathrm{PIP}_{2}$ levels through manipulation of PAP activity. Pap ${ }^{-1-}$ mice have elevated $\mathrm{PIP}_{2}$ levels in DRGs and enhanced LPA-, ATP-, CFA-, and nerve injuryinduced nociceptive sensitization [data above and in the study by Zylka et al. (2008)]. Conversely, S-hPAP injections reduced $\mathrm{PIP}_{2}$ levels in DRGs and enduringly inhibited LPA-, ATP-, CFA-, and nerve injury-induced nociceptive sensitization. S-hPAP acted exclusively through $\mathrm{A}_{1} \mathrm{R}$ to mediate these enduring effects (supplemental Fig. S6, available at www.jneurosci.org as supplemental material), ruling out the possibility that PAP acted through other adenosine receptor subtypes, including $\mathrm{A}_{2 \mathrm{~A}}$ (Loram et al., 2009). Importantly, these alterations in nociceptive sensitization outlasted the $3 \mathrm{~d}$ antinociceptive effects of S-hPAP and the acute (2 h) elevation of $\mathrm{PIP}_{2}$, arguing that neither maintained activity of PAP nor long-term elevations of $\mathrm{PIP}_{2}$ contributed to these enduring effects. Instead, these long-term changes in nociceptive sensitization could be attributable to reduced or enhanced engagement of transcriptional and nontranscriptional mechanisms that are downstream of pronociceptive receptor/PLC stimulation (Ji et al., 2009).

Intrathecal injections target DRGs and spinal cord (Luo et al., 2005). This raises the question of precisely where S-hPAP and $\mathrm{PIP}_{2}$ act to regulate nociception. Since S-hPAP (intrathecally) regulates $\mathrm{PIP}_{2}$ levels and nociception through $\mathrm{A}_{1} \mathrm{R}$ (data above) (Zylka et al., 2008), S-hPAP has the potential to act on any cell that expresses $A_{1} R$. This includes peptidergic and nonpeptidergic nociceptive neurons as well as postsynaptic neurons in the spinal cord (Reppert et al., 1991; Li and Perl, 1994; Lao et al., 2001; Schulte et al., 2003) but excludes microglial cells because they do not express $A_{1} R$ (Orr et al., 2009). Despite repeated attempts, we were unable to determine at a cellular level which DRG neurons incorporated $\mathrm{PIP}_{2}$ (by studying the distribution of $\mathrm{PIP}_{2}$ conjugated to fluorochromes) (data not shown). However, nociception was only affected over the time period in which $\mathrm{PIP}_{2}$ levels were elevated in DRGs, arguing that nociceptive neurons in DRGs were targeted. Furthermore, the elevated levels of $\mathrm{PIP}_{2}$ in DRGs from $P a p^{-1-}$ mice are likely to be restricted to the subset of peptidergic and nonpeptidergic nociceptive neurons that normally express PAP (Zylka et al., 2008). We cannot further pinpoint at the cellular level where S-hPAP and $\mathrm{PIP}_{2}$ act to regulate nociception with existing technologies.

Last, $\mathrm{PIP}_{2}$ levels can be increased or decreased relative to an intermediate level in DRGs (Fig. 3A,D), suggesting nociception may be influenced by an underlying "phosphoinositide tone." This tone may be coordinated with the "adenosine tone" that is present in diverse tissues, including the nervous system (Boison, 2008). Our data indicate that adenosine-generating ectonucleotidases like PAP contribute to this underlying phosphoinositide tone both positively and negatively. It may thus be possible to harness any molecule or mechanism that causes a sustained reduction in this tone to enduringly prevent or treat symptoms associated with chronic pain.

\section{References}

Basbaum AI, Bautista DM, Scherrer G, Julius D (2009) Cellular and molecular mechanisms of pain. Cell 139:267-284.

Bernier LP, Ase AR, Chevallier S, Blais D, Zhao Q, Boué-Grabot E, Logothetis D, Séguéla P (2008) Phosphoinositides regulate P2X 4 ATP-gated channels through direct interactions. J Neurosci 28:12938-12945.

Bhave G, Zhu W, Wang H, Brasier DJ, Oxford GS, Gereau RW 4th (2002) cAMP-dependent protein kinase regulates desensitization of the capsaicin receptor (VR1) by direct phosphorylation. Neuron 35:721-731.

Bhave G, Hu HJ, Glauner KS, Zhu W, Wang H, Brasier DJ, Oxford GS, Gereau RW 4th (2003) Protein kinase C phosphorylation sensitizes but does not activate the capsaicin receptor transient receptor potential vanilloid 1 (TRPV1). Proc Natl Acad Sci U S A 100:12480-12485.

Boison D (2008) Adenosine as a neuromodulator in neurological diseases. Curr Opin Pharmacol 8:2-7.

Burnstock G (2007) Physiology and pathophysiology of purinergic neurotransmission. Physiol Rev 87:659-797.

Campagnola L, Wang H, Zylka MJ (2008) Fiber-coupled light-emitting diode for localized photostimulation of neurons expressing channelrhodopsin-2. J Neurosci Methods 169:27-33

Caterina MJ, Schumacher MA, Tominaga M, Rosen TA, Levine JD, Julius D (1997) The capsaicin receptor: a heat-activated ion channel in the pain pathway. Nature 389:816-824.

Caterina MJ, Leffler A, Malmberg AB, Martin WJ, Trafton J, Petersen-Zeitz KR, Koltzenburg M, Basbaum AI, Julius D (2000) Impaired nociception and pain sensation in mice lacking the capsaicin receptor. Science 288:306-313.

Dale C, Vergnolle N (2008) Protease signaling to G protein-coupled receptors: implications for inflammation and pain. J Recept Signal Transduct Res 28:29-37.

Davis JB, Gray J, Gunthorpe MJ, Hatcher JP, Davey PT, Overend P, Harries MH, Latcham J, Clapham C, Atkinson K, Hughes SA, Rance K, Grau E, Harper AJ, Pugh PL, Rogers DC, Bingham S, Randall A, Sheardown SA (2000) Vanilloid receptor-1 is essential for inflammatory thermal hyperalgesia. Nature 405:183-187.

Dickenson JM, Hill SJ (1998) Involvement of G-protein betagamma subunits in coupling the adenosine A1 receptor to phospholipase $\mathrm{C}$ in transfected CHO cells. Eur J Pharmacol 355:85-93.

Di Paolo G, De Camilli P (2006) Phosphoinositides in cell regulation and membrane dynamics. Nature 443:651-657.

Dolphin AC, Forda SR, Scott RH (1986) Calcium-dependent currents in cultured rat dorsal root ganglion neurones are inhibited by an adenosine analogue. J Physiol 373:47-61.

Eisenach JC, Rauck RL, Curry R (2003) Intrathecal, but not intravenous adenosine reduces allodynia in patients with neuropathic pain. Pain 105:65-70.

Elmes SJ, Millns PJ, Smart D, Kendall DA, Chapman V (2004) Evidence for biological effects of exogenous LPA on rat primary afferent and spinal cord neurons. Brain Res 1022:205-213.

Fairbanks CA (2003) Spinal delivery of analgesics in experimental models of pain and analgesia. Adv Drug Deliv Rev 55:1007-1041.

Gamper N, Reznikov V, Yamada Y, Yang J, Shapiro MS (2004) Phosphatidylinositol 4,5-bisphosphate signals underlie receptor-specific Gq/11-mediated modulation of N-type $\mathrm{Ca}^{2+}$ channels. J Neurosci 24:10980-10992.

Huang J, Zhang X, McNaughton PA (2006) Inflammatory pain: the cellular basis of heat hyperalgesia. Curr Neuropharmacol 4:197-206.

Hucho T, Levine JD (2007) Signaling pathways in sensitization: toward a nociceptor cell biology. Neuron 55:365-376.

Inoue M, Rashid MH, Fujita R, Contos JJ, Chun J, Ueda H (2004) Initiation of neuropathic pain requires lysophosphatidic acid receptor signaling. Nat Med 10:712-718.

Jacobson KA, Gao ZG (2006) Adenosine receptors as therapeutic targets. Nat Rev Drug Discov 5:247-264.

Ji RR, Gereau RW 4th, Malcangio M, Strichartz GR (2009) MAP kinase and pain. Brain Res Rev 60:135-148.

Kelley GG, Kaproth-Joslin KA, Reks SE, Smrcka AV, Wojcikiewicz RJ (2006) G-protein-coupled receptor agonists activate endogenous phospholipase Cepsilon and phospholipase Cbeta3 in a temporally distinct manner. J Biol Chem 281:2639-2648.

Kim AY, Tang Z, Liu Q, Patel KN, Maag D, Geng Y, Dong X (2008) Pirt, a phosphoinositide-binding protein, functions as a regulatory subunit of TRPV1. Cell 133:475-485. 
Klein RM, Ufret-Vincenty CA, Hua L, Gordon SE (2008) Determinants of molecular specificity in phosphoinositide regulation. Phosphatidylinositol $(4,5)$-bisphosphate $\left(\mathrm{PI}(4,5) \mathrm{P}_{2}\right)$ is the endogenous lipid regulating TRPV1. J Biol Chem 283:26208-26216.

Kwon Y, Hofmann T, Montell C (2007) Integration of phosphoinositideand calmodulin-mediated regulation of TRPC6. Mol Cell 25:491-503.

Lao LJ, Kumamoto E, Luo C, Furue H, Yoshimura M (2001) Adenosine inhibits excitatory transmission to substantia gelatinosa neurons of the adult rat spinal cord through the activation of presynaptic $A_{1}$ adenosine receptor. Pain 94:315-324.

Li J, Perl ER (1994) Adenosine inhibition of synaptic transmission in the substantia gelatinosa. J Neurophysiol 72:1611-1621.

Lin CW, Yan F, Shimamura S, Barg S, Shyng SL (2005) Membrane phosphoinositides control insulin secretion through their effects on ATPsensitive $\mathrm{K}^{+}$channel activity. Diabetes 54:2852-2858.

Lishko PV, Procko E, Jin X, Phelps CB, Gaudet R (2007) The ankyrin repeats of TRPV1 bind multiple ligands and modulate channel sensitivity. Neuron 54:905-918.

Liu B, Zhang C, Qin F (2005) Functional recovery from desensitization of vanilloid receptor TRPV1 requires resynthesis of phosphatidylinositol 4,5-bisphosphate. J Neurosci 25:4835-4843.

Loram LC, Harrison JA, Sloane EM, Hutchinson MR, Sholar P, Taylor FR, Berkelhammer D, Coats BD, Poole S, Milligan ED, Maier SF, Rieger J, Watkins LR (2009) Enduring reversal of neuropathic pain by a single intrathecal injection of adenosine $2 \mathrm{~A}$ receptor agonists: a novel therapy for neuropathic pain. J Neurosci 29:14015-14025.

Lukacs V, Thyagarajan B, Várnai P, Balla A, Balla T, Rohacs T (2007) Dual regulation of TRPV1 by phosphoinositides. J Neurosci 27:7070-7080.

Luo MC, Zhang DQ, Ma SW, Huang YY, Shuster SJ, Porreca F, Lai J (2005) An efficient intrathecal delivery of small interfering RNA to the spinal cord and peripheral neurons. Mol Pain 1:29.

Ma L, Matsumoto M, Xie W, Inoue M, Ueda H (2009) Evidence for lysophosphatidic acid 1 receptor signaling in the early phase of neuropathic pain mechanisms in experiments using Ki-16425, a lysophosphatidic acid 1 receptor antagonist. J Neurochem 109:603-610.

Mills GB, Moolenaar WH (2003) The emerging role of lysophosphatidic acid in cancer. Nat Rev Cancer 3:582-591.

Milosevic I, Sørensen JB, Lang T, Krauss M, Nagy G, Haucke V, Jahn R, Neher E (2005) Plasmalemmal phosphatidylinositol-4,5-bisphosphate level regulates the releasable vesicle pool size in chromaffin cells. J Neurosci 25:2557-2565.

Murthy KS, Makhlouf GM (1995) Adenosine A1 receptor-mediated activation of phospholipase C-beta 3 in intestinal muscle: dual requirement for alpha and beta gamma subunits of Gi3. Mol Pharmacol 47:1172-1179.

Nakagawa T, Wakamatsu K, Zhang N, Maeda S, Minami M, Satoh M, Kaneko S (2007) Intrathecal administration of ATP produces long-lasting allodynia in rats: differential mechanisms in the phase of the induction and maintenance. Neuroscience 147:445-455.

Narita M, Ohsawa M, Mizoguchi H, Aoki T, Suzuki T, Tseng LF (2000) Role of the phosphatidylinositol-specific phospholipase C pathway in deltaopioid receptor-mediated antinociception in the mouse spinal cord. Neuroscience 99:327-331.

Orr AG, Orr AL, Li XJ, Gross RE, Traynelis SF (2009) Adenosine $A_{2 A}$ receptor mediates microglial process retraction. Nat Neurosci 12:872-878.

Ostanin K, Saeed A, Van Etten RL (1994) Heterologous expression of human prostatic acid phosphatase and site-directed mutagenesis of the enzyme active site. J Biol Chem 269:8971-8978.
Ozaki S, DeWald DB, Shope JC, Chen J, Prestwich GD (2000) Intracellular delivery of phosphoinositides and inositol phosphates using polyamine carriers. Proc Natl Acad Sci U S A 97:11286-11291.

Park KA, Vasko MR (2005) Lipid mediators of sensitivity in sensory neurons. Trends Pharmacol Sci 26:571-577.

Prescott ED, Julius D (2003) A modular PIP2 binding site as a determinant of capsaicin receptor sensitivity. Science 300:1284-1288.

Reppert SM, Weaver DR, Stehle JH, Rivkees SA (1991) Molecular cloning and characterization of a rat Al-adenosine receptor that is widely expressed in brain and spinal cord. Mol Endocrinol 5:1037-1048.

Rohacs T, Thyagarajan B, Lukacs V (2008) Phospholipase C mediated modulation of TRPV1 channels. Mol Neurobiol 37:153-163.

Sawynok J (2007) Adenosine and ATP receptors. Handb Exp Pharmacol 177:309-328.

Schneider G, Lindqvist Y, Vihko P (1993) Three-dimensional structure of rat acid phosphatase. EMBO J 12:2609-2615.

Schulte G, Robertson B, Fredholm BB, DeLander GE, Shortland P, Molander C (2003) Distribution of antinociceptive adenosine A1 receptors in the spinal cord dorsal horn, and relationship to primary afferents and neuronal subpopulations. Neuroscience 121:907-916.

Shields SD, Eckert WA 3rd, Basbaum AI (2003) Spared nerve injury model of neuropathic pain in the mouse: a behavioral and anatomic analysis. J Pain 4:465-470.

Sowa NA, Vadakkan KI, Zylka MJ (2009) Recombinant mouse PAP has $\mathrm{pH}$-dependent ectonucleotidase activity and acts through $\mathrm{A}_{1}$-adenosine receptors to mediate antinociception. PLoS ONE 4:e4248.

Sowa NA, Taylor-Blake B, Zylka MJ (2010) Ecto-5'-nucleotidase (CD73) inhibits nociception by hydrolyzing AMP to adenosine in nociceptive circuits. J Neurosci 30:2235-2244.

Stein AT, Ufret-Vincenty CA, Hua L, Santana LF, Gordon SE (2006) Phosphoinositide 3-kinase binds to TRPV1 and mediates NGF-stimulated TRPV1 trafficking to the plasma membrane. J Gen Physiol 128:509-522.

Suh BC, Hille B (2005) Regulation of ion channels by phosphatidylinositol 4,5-bisphosphate. Curr Opin Neurobiol 15:370-378.

Várnai P, Balla T (1998) Visualization of phosphoinositides that bind pleckstrin homology domains: calcium- and agonist-induced dynamic changes and relationship to myo- $\left[{ }^{3} \mathrm{H}\right]$ inositol-labeled phosphoinositide pools. J Cell Biol 143:501-510.

Várnai P, Thyagarajan B, Rohacs T, Balla T (2006) Rapidly inducible changes in phosphatidylinositol 4,5-bisphosphate levels influence multiple regulatory functions of the lipid in intact living cells. J Cell Biol 175:377-382.

Vihko P (1978) Characterization of the principal human prostatic acid phosphatase isoenzyme, purified by affinity chromatography and isoelectric focusing. Part II. Clin Chem 24:1783-1787.

Wang H, Ehnert C, Brenner GJ, Woolf CJ (2006) Bradykinin and peripheral sensitization. Biol Chem 387:11-14.

Wu WP, Hao JX, Halldner L, Lövdahl C, DeLander GE, Wiesenfeld-Hallin Z, Fredholm BB, Xu XJ (2005) Increased nociceptive response in mice lacking the adenosine A1 receptor. Pain 113:395-404.

Yao J, Qin F (2009) Interaction with phosphoinositides confers adaptation onto the TRPV1 pain receptor. PLoS Biol 7:e46.

Zylka MJ, Sowa NA, Taylor-Blake B, Twomey MA, Herrala A, Voikar V, Vihko P (2008) Prostatic acid phosphatase is an ectonucleotidase and suppresses pain by generating adenosine. Neuron 60:111-122. 